\title{
A financial macro-network approach to climate policy evaluation
}

\author{
Veronika Stolbova $^{\mathrm{a}, \mathrm{b}}$, Irene Monasterolo ${ }^{\mathrm{c}, \mathrm{d}}$, Stefano Battiston ${ }^{\mathrm{a}, \mathrm{e}}$ \\ ${ }^{a}$ FINEXUS Center for Financial Networks and Sustainability, Department of Banking and Finance, \\ University of Zurich \\ ${ }^{b}$ Potsdam Institute for Climate Impact Research (PIK) \\ ${ }^{c}$ Vienna University of Economics and Business \\ ${ }^{d}$ Boston University \\ ${ }^{e}$ Swiss Finance Institute
}

\begin{abstract}
Existing approaches to assess the economic impact of climate policies tend to overlook the financial sector and to focus only on direct effects of policies on the specific institutional sector they target, neglecting possible feedbacks between sectors, thus, underestimating the overall policy effect. To fill in this gap, we develop a methodology based on financial networks, which allows for analyzing the transmission throughout the economy of positive or negative shocks induced by the introduction of specific climate policies. We apply the methodology to empirical data of the Euro Area to identify the feedback loops between the financial sector and the real economy both through direct and indirect chains of financial exposures across multiple financial instruments. By focusing on climate policy-induced shocks that affect directly either the banking sector or non-financial firms, we analyze the reinforcing feedback loops that could amplify the effects of shocks on the financial sector and then cascade on the real economy. Our analysis helps to understand the conditions for virtuous or vicious cycles to arise in the climate-finance nexus and to provide a comprehensive assessment of the economic impact of climate policies.

Keywords: financial networks, feedback loops, climate policies, shock transmission channels, indirect effects, low-carbon transition.
\end{abstract}

\section{Highlights:}

- We propose a methodology to assess the economic impact of climate policies

- It builds on financial macro-network analysis across multiple instruments 
- We apply this methodology to empirical data of financial exposures in the Euro Area

- We analyze climate policy-induced shock transmission on finance/economic sectors

- We identify critical feedback loops that reinforce the climate policy-induced shocks

1

\section{Introduction}

(1) societies but also for the performance of the real economy (IPCC, 2014) and for the stability of the financial system (Carney, 2015, ESRB, 2016). Indeed, in order to limit the negative impact of human activities on the climate, there is a need for a reallocation of private and public financial investments from carbon-intensive to low-carbon economic activities (HLEGSust-Fin, 2017). There is a broad consensus on the fact that such reallocation of financial capital is not possible through purely market-based solutions and that ambitious economic policies aimed to foster the transition to a low-carbon economy, i.e. climate policies hereafter, are needed (EC, 2015, Maxton and Randers, 2016). In turn, the introduction of climate policies comes with a significant risk for those financial investors who are locked-in into high-carbon investments (the so-called climate transition risk, Carney, 2015), and thus exposed to a loss of value resulting from "carbon stranded assets" (Leaton, 2012, Caldecott and McDaniels, 2014). Overall, the global climate "Value at Risk" (VaR) due to climate-induced physical damages has been estimated as approximately 24 trillion USD of lost financial asset (Dietz et al. 2016). Further, a climate stress-test of the financial system (Battiston et al. 2017) shows that the combined exposure of financial actors' equity holdings portfolios to climate-policy-relevant sectors (i.e. sectors that are directly or indirectly responsible for greenhouse gases (GHG) emissions and thus more vulnerable in case of climate policies) is considerable, reaching up to $45 \%$ of the equity portfolio of pension funds. In addition, financial actors' interconnectedness across the interbank market and other markets could amplify distress through reverberation effects, with potential implications on systemic risk (Battiston et al., 2017). Indeed, in a mild scenario, volatility on climate-policy-relevant sectors affects individual financial actors while in 
a severe scenario, systemic adverse effects could occur. These findings imply that the assessment of climate policies impacts on the financial system is crucial.

This paper aims to investigate how economic shocks arising from the "too-late-and-toosudden" introduction of climate policies (ESRB, 2016) can be amplified through feedback loops of chains of financial exposures in the economy. We start from the observation that climate change leads to technological and policy shocks that invalidate the Rational Expectations Hypothesis $(\mathrm{REH})$. Indeed, there are several examples of climate-related technological and policy shocks on asset prices that market players are not able to fully anticipate even on average (Monasterolo et al., 2017). Examples of unanticipated technological shocks include the fasterthan-expected decrease in renewable energy costs in last decade. Examples of unanticipated policy shocks include the fact that in 2014 most observers would not believe in the achievement of the Paris Agreement in 2015, while in 2016 most observers would not predict the subsequent US withdrawal from the Paris Agreement in 2017.

These examples imply that, at a time scale relevant for decision making, agents' expectations on prices can be incorrect, even on average. This fact contradicts the REH and implies the possibility of systematic mispricing of assets. In turn, the invalidation of the REH and the possibility of systematic mispricing has deep implications on the role of finance in the impact of policy shocks on the economy as a whole. Due to the fact that many markets are decentralized, the market players are exposed to counterparty risk through financial contracts. In these markets, the recovery rate $r$ denotes the fraction of the nominal value of the contract that a party obtains from an obligor, in case of its default. If the REH does not hold and there is the possibility of systematic mispricing on a given asset class, then the recovery rate on the obligations of all actors directly exposed to that asset class can be significantly smaller than one, even in expectation. Since the obligations of those first actors are assets for the second group of actors, the expected value of the assets of the second group can be systematically overpriced. In a mark-to-market accounting environment where market players make decisions based on the expected value of their counterparties obligations, the initial mispricing on a given asset class implies the propagation of potential losses along the chains of financial contracts (Battiston et al., 2016c b; Bardoscia et al. 2017). Further, as we show in this paper, the presence of 
closed chains of contracts leads to feedback loops that not only propagate shocks from a sector to another but also amplify their magnitude. Because in todays economy financial contracts form intricate networks, and feedback loops are present at many levels, their role needs to be examined. In particular, climate policy shocks hitting actors in the financial system could cascade to those of the real economy, and the impact of this shocks could get amplified by the feedback loops that characterize the real-financial linkages. The process of financialization of the economy in the last two decades (Palley, 2016) suggests that the magnitude of the amplification effect could be increasing.

In contrast, standard economic models for climate policies' evaluation focus on the economic costs of climate policies (Nordhaus, 1993, 2016, Revesz et al., 2014), and in doing so, they tend to rely on the REH and to overlook the role of the financial sector. In particular, they neglect possible feedback loops between sectors and they are therefore unsuited to assess the full financial impact of climate policies on the economy. In order to fill this gap, we develop a methodology based on accounting principles and a multi-layer network analysis that aims to estimate the potential amplification of shocks along feedback loops consisting of closed chains of financial exposures among institutional sectors in the economy. Our approach contributes to understanding to what extent (possibly delayed) climate policies could lead to amplification effects in case of banks' high leverage and a recovery rate lower than one. We estimate the main reinforcing feedback loops between the financial sector and the real economy based on Euro Area balance sheet and cross-sectors data.

The paper is structured as follows. In section 2, we provide a review of Related Work. In section 3, we present the Analytical results where we introduce our methodology based on multilayer financial networks for the analysis of direct and indirect effects of climate policies. In section 4, we present the Empirical results where we discuss data used in the study, and two mechanisms of climate policy shock transmission. We conclude with section 5 , discussing the contribution of our methodology to climate-policy evaluation, which is followed by Appendix section containing the proofs of the propositions and other details.

\section{Related work}


Policy-makers and regulators could play a defining role in meeting the Paris Agreement by designing the right incentives, and by implementing the adequate policy mix for a smooth lowcarbon transition. In the current policy debate, the most discussed climate policies (and thus the more likely to be introduced in the near-future, see HLEG-Sust-Fin, 2018) are as follows:

- Market-based solutions, such as a carbon tax, i.e. the introduction of a tax on carbon emissions produced by economic sectors and activities (CPLC, 2017),

- Green macroprudential regulations such as differentiated banks' capital requirements (Volz, 2017; HLEG-Sust-Fin, 2018),

- Green unconventional monetary policies, such as a green Quantitative Easing (QE) implemented by the central bank through the purchase of green assets (e.g. green bonds) from the banks (Campiglio, 2016; Monasterolo and Raberto, 2018; Barkawi, 2017).

In order for the financial sector to be a part of the sustainability solution, the discussion about the timing and magnitude of climate policies should explicitly target finance, for at least two reasons. First, the implementation of climate policies could imply shocks for the financial system, and, in particular, for those financial actors who are both vulnerable yet relevant (Monasterolo et al. 2017). Second, the transition of the financial sector towards sustainability, including portfolios' decarbonization and the introduction of novel financial instruments, is considered as a precondition to achieving the EU2030 energy and climate targets (HLEG-Sust-Fin, 2017). It follows that in order to design and implement effective and targeted climate policies, policy-makers need to rely on tools for economic policy analysis that provide information on the following:

- The structure of the financial system and the relation between the financial system and the real economy (e.g. households, firms, government).

- How shocks generated by the introduction of climate policies could spread through the network of interconnected financial actors (i.e. shock transmission channels), and from there to the sectors and agents of the real economy. Recent analyses show that the interconnectedness of financial institutions could amplify both positive and negative shocks and 
significantly decrease the accuracy of estimations of default probabilities (Battiston et al. $2016 \mathrm{a}$ b), thus, increasing the complexity of risk estimation.

- The presence of reinforcing and balancing feedback loops and their effects through direct and indirect shocks' transmission channels. For instance, the introduction of unconventional monetary policies (e.g. a green QE aimed to scale-up green capital investments) could induce shocks on the financial system (e.g. financial stranded assets) that could then affect the real economy (e.g. via shifting to green investments).

The concept of feedback loops is fundamental and is at the core of the analysis of the mechanisms driving the behavior pattern of a system over time (Sterman, 2000, Meadows, 2008). The analysis of feedback loops at work in a system allows to identify the presence of three main elements for climate policy analysis:

- time delays between the imposition of a shock and further shocks due to the agents' reactions,

- tipping points beyond which the characteristics of the system could dramatically change,

- the presence of reinforcing mechanisms, which often give rise to problems of path-dependency.

In addition, the analysis of the dynamic interplay of feedback loops contributes to the explanation of emerging non-linear behaviors that are often not intuitively understood and that could give rise to emerging, unintended, macroeconomic consequences. Despite aforementioned facts, the analysis of feedback loops is usually overlooked by existing approaches for climate and economic policy assessment, such as Integrated Assessment Models (IAMs) (see for instance Kriegler et al. 2013) and Computable General Equilibrium Models (CGEs) (Böhringer and Löschel, 2006) and the Dynamic Stochastic General Equilibrium Models (DSGEs). Therefore, Rezai and Stagl (2016) called for the development of a new generation of models in ecological macroeconomics to integrate the micro-foundations of the models with a meso- and macroeconomic analysis, including the consideration of modern financial system and the consideration of distributive effects. This would allow a better understanding of the feedback loops between 
the ecosystem, the real economy and the financial sector, as well as to account for policies' distributive effects.

CGE, IAM, and DSGEs are rooted on the neoclassical economic theory and have contributed by a great extent to the increasing attention of the economic discipline to the drivers and impacts of climate change, and to micro and macroeconomics stylized facts. In the last decade, some of these models have introduced relevant novelties, such as endogenous technological innovation (e.g., the WITCH IAM, see Bosetti et al.|2006), and the differentiation of fossil fuel-based and renewable energy sources by energy industry (Kriegler et al., 2013; Calvin et al., 2013). DSGEs have also been complemented with relevant previously missing features (Monasterolo and Raberto, 2018) that allow the representation of real business cycles, the analysis of unconventional monetary policies (Coibion et al., 2017; Saiki and Frost, 2014), a stylized description of a modern money system and endogenous money creation (Jakab and Kumhof, 2014), and an environmental focus (Golosov et al. 2014; Annicchiarico and Di Dio, 2016).

Nevertheless, there is growing concern among academics and practitioners that neither IAMs and CGEs (Balint et al., 2017; Farmer et al., 2015; Mercure et al., 2016) nor DSGE (Romer, 2016; Blanchard, 2018; Haldane and Turrell, 2018; Stiglitz, 2018) are appropriate to adequately account for the drivers of endogenous feedbacks between interconnected financial actors, the nonlinearities and tipping points that characterize climate change, and the shocks' transmission channels from climate policies to financial actors and actors of the real economy.

The models' common critical points can be summed up in the following:

- the adoption of strong assumptions on markets and agents' behaviors and expectations, where the economy is composed by representative agents that maximize a utility function (Kirman, 1992), thus reducing the number of possible equilibria to a single one, and immediately react to policies;

- the assumption of optimal allocation of all resources in the Business As Usual (BAU) case, which neglects the possibility of underutilized or not efficiently utilized financial resources;

- a very stylized representation of the financial sector (if any) that neglects money (i.e. 
prices are relative prices), the importance of financial actors' interconnectedness and real-financial linkages that can amplify shocks;

- a limited understanding of modern money theory as regards the endogenous creation of money by credit institutions and the flow of money between the economic and the financial system (Wray, 2015; McLeay et al., 2014);

- the representation of climate policies by adding emissions and their accumulation in the atmosphere. This leads to consideration of the climate mitigation as an additional constraint and as a short-term cost rather than a long-term benefit for the economy (Wolf et al. 2016).

Recently, also Stock-Flow Consistent modeling approaches (e.g. Dafermos et al. (2017)) and Agent-Based Models (Lamperti et al., 2017) highlighted the economic cost (in terms of GDP) of climate policies. However, recent analyses show that win-win options could arise from the introduction of either fiscal or monetary policies aimed to mitigate climate change and to support the low-carbon transition (Lamperti et al., 2016; Ponta et al., 2016; Monasterolo and Raberto, 2018).

In order to provide a comprehensive and robust assessment of climate policies' impact on the financial system, and from there to the real economy, we need approaches able to overcome such limitations. In this paper, we explore the contribution of financial networks to analyze the direct and indirect effects of climate policies at the sector level, considering shock propagation and amplification from the financial sector to the real economy. To this extent, our analysis relates to the large stream of work investigating the propagation of distress in financial networks (Markose et al. 2017, Cimini et al., 2015; Battiston et al., 2016c). Financial networks consist of a set of both financial or non-financial firms and the financial contracts they establish among each other, including equity holdings, loans, tradable debt obligations (i.e. bonds) and derivatives. In a mark-to-market accounting environment, negative shocks on equity values of firms result in changes in the equities values of the other firms holding their debt obligations (Battiston et al., 2016c b Bardoscia et al., 2017). The mechanism works as follows: a decrease in firms' equity translates into an increase of its probability of defaulting on their obligations and, thus, 
in a decrease in the value of firms' obligations. Firms holding these obligations experience a decrease in value of their own asset side and, therefore, of their equity (as the difference between asset and liabilities).

Recently, Barucca et al. (2016) have shown analytically how to describe the propagation of shocks across firms' obligations while respecting the balance-sheet identity of all firms under very general conditions on the contracts, covering the case of loans and bonds. These conditions require, in simple terms, that upon a decrease in the equity value of the obligor, the valuation of its obligation can only decrease. This result is important in the context of the present paper because even when contracts are aggregated at the level of financial exposures among economic sectors, we can still argue that negative shocks on firms in one sector translate in negative shocks on the firms in another sector if the latter are exposed to debt obligations of firms in the first sector. The first step into the direction of estimation of shock propagation between the sectors was done by Castrén and Rancan (2014), where the authors introduced the concept of macro-networks to describe the set of financial linkages within the economy aggregated at the level of institutional sectors. Despite the large body of works in financial networks and the specific stream of works on macro-networks, only very recent work has been applying this approach to the context of climate policies. In particular, the network-based climate stress-test developed in Battiston et al. (2017) allows to assess the exposure of individual institutions to climate risk. In contrast, in this paper, we focus our analysis at the sector level.

\section{Analytical Results}

\subsection{The financial macro-network approach}

At the micro-economic level, firms (e.g. individual banks, non-financial firms), households and governments establish financial contracts with each other through multiple financial instruments (i.e. loans, equity, bonds, and insurance\&pension schemes guarantees). As discussed in the introduction, economic actors cannot be assumed to fully anticipate shocks arising from climate change and associated policies. In this Section, with the aim to analyze how these shocks propagate through financial interdependencies and feedback loops between the financial 
sectors and the real economy sectors, we take a financial macro-network approach at the sector level (Castrén and Rancan, 2014).

This means that we look at the aggregated exposures of each institutional sector to the others, for each type of financial instrument. The advantage of analyzing an economy as a multilayer financial network calibrated on empirical data is threefold. First, we can estimate the direct and indirect financial dependencies in the economy. Second, by looking at closed chains of dependencies, we can identify the main feedback loops between the financial sector and the real economy, and analyze their drivers and intensity. Third, we use indirect dependencies and feedback loops to assess the main possible channels of shock transmission and amplification effect as a result of the introduction of late and sudden climate policies aimed at supporting the low-carbon transition.

Remark 1. Before describing the methodology in more detail, a relevant remark applies. It may be tempting to think that in the economic system, since one agent's asset is another agent's liability, then, in the aggregate, assets and liabilities can be simply netted out. This intuition is correct under the following conditions: i) there are no bankruptcy costs and no information asymmetry (Visentin et al., 2016; Bardoscia et al., 2016, 2017), or ii) debt contracts are fully collateralized with recovery rate close to one (in case of counterparty's default, Battiston et al., 2016c). However, in general, the above conditions do not hold and, as a result, the intuition about netting out is incorrect in many empirical situations that are relevant to the discussions on distress propagation and the impact of climate policies. Indeed, the presence of technological, scientific and policy shocks can hamper the ability of market players to fully anticipate price adjustments (even on average) of assets in the economic sectors directly involved in the lowcarbon transition (Monasterolo et al., 2017). This means that we cannot rule out systematic mispricing of assets and hence the condition that recovery rates on contracts can be significantly smaller than one in case of counterparties' default. Moreover, bankruptcy costs and asymmetry of information cannot be neglected, especially when markets are distressed (Battiston et al., 2016c). Under these conditions, it is legitimate and very important to look at the aggregate exposures without assuming the netting out of assets and liabilities. This fact has also been recognized by the ECB since the concept of financial macro-network was introduced to better 
understand and mitigate the propagation of financial distress in the aftermath of the 2008 financial crisis (Castrén and Rancan, 2014). In contrast, analysis of the sector level has, of course, the limitation of neglecting the diversity of the individual firms' balance-sheet structure and the diversity in the maturity of the contracts. However, it also has the advantage in terms of its ability to identify the most relevant channels of shock transmission in the economy as it allows to identify the exposure between the sectors of the economy through exposures of the leading firms in these sectors (see Proposition 2).

In the following of this section, we will prove a useful result concerning the meaning of aggregate exposures that lends methodological rigor to the macro-network approach but has not yet been emphasized in the literature. To this end, we first need to provide a few definitions.

Let us consider two sectors $i$ and $j$, with firms $l$ in the sector $i$, and firms $m$ in the sector $j$. Then, let us denote the exposure of a firm $l$ in the sector $i$ to a firm $m$ in the sector $j$ through instrument $k$ as $a_{l m}^{k}$. Then, total assets of firms in the sector $i$ through instrument $k$ is $A_{i}^{k}=\sum_{l} a_{l}^{k}$, and total exposure of the sector $i$ to the sector $j$ through instrument $k$ is $A_{i j}^{k}=\sum_{l, m} a_{l m}^{k}$, where $l \in i$, and $m \in j$.

Definition 1. The relative exposure of a given firm $l$ in the sector $i$ towards all firms in the sector $j$ through instrument $k$ is defined as

$$
\frac{\sum_{m} a_{l m}^{k}}{a_{l}^{k}},
$$

where the sum goes over all firms $m$ in the sector $j$ to which the firm $l$ is exposed.

Definition 2. The weighted average of the relative exposure of the sector $i$ to the sector $j$ (weighted by total asset of firms in the sector $i$ through instrument $k$ ) is

$$
\frac{\sum_{l}\left(a_{l}^{k} \frac{\sum_{m} a_{l m}^{k}}{a_{l}^{k}}\right)}{\sum_{l} a_{l}^{k}} .
$$

Definition 3. The aggregate relative exposure of a sector $i$ to a sector $j$ through instrument $k$ is defined as

$$
\frac{A_{i j}^{k}}{A_{i}^{k}},
$$


where $A_{i}^{k}$ represents the total assets of a sector $i$ invested through instrument $k$, and where $A_{i j}^{k}$ is the total exposure of a sector $i$ to a sector $j$ through instrument $k$.

Proposition 1. The weighted average of the relative exposure of all firms $l$ in a sector $i$ to all firms $m$ in a sector $j$, weighted by total assets of firms, through instrument $k$, coincides with the aggregate relative exposure of a sector $i$ to a sector $j$ through instrument $k$ :

$$
\frac{\sum_{l}\left(a_{l}^{k} \frac{\sum_{m} a_{l m}^{k}}{a_{l}^{k}}\right)}{\sum_{l} a_{l}^{k}}=\frac{A_{i j}^{k}}{A_{i}^{k}} .
$$

\section{Proof. See Appendix A}

Proposition 2. Assumption: the top q actors by total assets represent $(1-\epsilon)$ of total assets of sector $i$. Then, in the limit of $\epsilon \rightarrow 0$ the aggregate relative exposure of a sector $i$ to a sector $j$ coincides with the average of the exposures of the top $q$ actors, weighted by their total assets, in sector $i$ towards sector $j$.

Proof. See Appendix A.

The above result implies that if the distribution of actors' total assets is skewed, then a large aggregate exposure between a sector $i$ and a sector $j$ implies large exposures of the top $q$ actors (by their total assets) of a sector $i$ to actors in the sector $j$. Notice that this statement is valid both for financial exposures (see Section 3.6.1) and for leverage links (see Section 3.6.2).

In the following, we want to show how chains of exposures at the microeconomic level can give rise to chains of exposures at the macroeconomic level. In order to do so, we need to introduce the following definitions and in particular, the notions of financial micro- and macro-networks.

Definition 4. A network is defined as a collection of items denoted as nodes, and a collection of ordered relations between pairs of items denoted as links. In a weighted network, links are associated with a real number in respect with a significance of the link (the bigger the number the more significant the link is). Further, if links can be of different types, the network is called multilayer, in the sense that each type of links corresponds to one layer. 
Definition 5. A financial micro-network is a network with individual firms as nodes and links as financial interdependencies between these firms, usually, in terms of financial contracts (e.g. equity shares, bonds and loans holdings).

Definition 6. A financial macro-network is a network in which nodes are economic sectors (e.g banks, non-financial firms, investment fund), and links are aggregate exposures among pairs of sectors along a specific type of financial instruments (i.e. equity, bonds, loans or insurance\&pension schemes guarantees). Each type of a financial instrument marks a layer in the financial macro-network.

Definition 7. A closed chain of exposures in the financial network is a chain of exposures between the nodes of the financial network either between firms or sectors that starts and ends in the same node of the financial network.

It is possible to provide sufficient conditions for the existence of chains of exposures in the micro-network if there are exposures in the macro-network, as formalized in the following proposition.

Proposition 3. Assumption: for each sector in a closed chain of exposures in a macro-network, all top $q$ actors in a given sector $i$ are linked to at least one of the top $q$ actors in the following sector $j$ in the chain. Then, there exist some closed chains of exposures in the micro-network of financial contracts between the firms in sectors $i$ and $j$.

Proof. See Appendix A.

The above proposition implies that given a chain of exposures at the macro-level, and under the mild assumption stated there, there also exist chains at the micro-level. This means that although shocks propagate only at the micro-level i.e. from a firm to another through chains of individual contracts, it is also reasonable to talk about distress propagation from a sector to another through chains of aggregate exposures. The propagation of distress through the macro-network of financial exposures between the sectors is the result of the aggregation of shocks propagated through the financial contracts between individual firms. Thus, the shock 
propagation through the macro-network reflects the aggregated shock propagation through the micro-network of financial contracts.

Given that shocks propagate along individual contracts between the firms (micro-level) but individual contracts are not available, this is a strong argument to use the aggregate data for exposures between the sectors across different instruments as a proxy of individual exposures between the firms from these sectors. In other words, if the aggregate exposure of a sector $i$ to a sector $j$ is large relative to the aggregate balance sheet of a sector $i$, this implies that aggregate relative exposure of individual actors within sector $i$ to individual actors in sector $j$ is also large.

Taking into account the argument above, in this study, we reconstruct and analyze a multilayer financial macro-network of institutional sectors (see section 4.1 for data description, and Appendix Appendix B- for the detailed description of sectors), where links represent aggregate exposures among pairs of sectors along a specific type of financial instruments (i.e. equity, bonds, loans or insurance\&pension schemes guarantees). The weight of a link represents the monetary value of the financial exposure (relative to total assets of the sector that bears the exposure) along a given instrument. Overall, since financial contracts vary in size across various instruments (i.e. loans, equity, bonds, and insurance\&pension schemes guarantees), the economy on a macro-level can be represented as a multilayer weighted and directed network. In this study, the direction of the link is specified from the sector which holds the asset to the sector which issues the asset.

The balance sheet of institutional sector $i$ (e.g. non-financial firms, banks, investment funds, other financial institutions, government, households, insurance\&pension funds) at a given time $t$ is described as follows:

$$
A_{i}(t)=\sum_{j, k} A_{i j}^{k}(t)+S_{i}(t),
$$

where $A_{i}$ is the value of total assets of an institutional sector $i, A_{i j}^{k}$ is the exposure of an institutional $i$ to institutional sector $j$ through instrument $k$, and $S_{i}$ is the rest of the assets (i.e. the total assets excluding equity shares, bond holdings, loans and deposits holdings, and holdings of insurance and pension schemes guarantees). In this paper we consider the 
following institutional sectors $(i, j)$ : non-financial firms, banks, investment funds, other financial institutions, government, households, insurance\&pension funds. The institutional sectors are linked through the following instruments $(k)$ : equity, bonds, loans, insurance\&pension schemes guarantees.

Taking into account that the exposure of the institutional sector $i$ to institutional sector $j$ is defined as $A_{i j}=\sum_{k} A_{i j}^{k}$ (since we consider a fixed time snapshot, we omit $t$ ), we define the relative exposure of the sector $i$ to the sector $j$ :

Definition 8. The relative exposure of the sector $i$ to the sector $j$ is defined as follows:

$$
w_{i j}=\frac{A_{i j}}{A_{i}} .
$$

\subsection{Reinforcing and balancing feedback loops between the financial sectors and sectors of the} real economy

Here we extend the concept and the application of feedback loops (Sterman, 2000, 2002) to the context of the macro-network of financial interdependencies. This extension is relevant for the assessment of the overall impact of the introduction of a climate policy. Indeed, we assume that the introduction of a policy at time $t_{0}$ leads to a direct shock (positive or negative) on assets of a target institutional sector $i$. Let us denote the shock as $\Delta A_{i}\left(t_{0}\right)$, describing a change in a total assets of a targeted by policy institutional sector $i$ at time $t_{0}^{1}$. In the presence of chains of financial interdependencies among the institutional sectors, the shock can propagate from the sector $i$ to other institutional sectors. Further, in the presence of a closed chain of financial dependencies (referred to as a cycle hereafter) the shock eventually travels back to the sector $i$ where it originated. At this time, $t_{n}$, the magnitude of the shock $\Delta A_{i}\left(t_{n}\right)$ can either be amplified or dampened in comparison with the initial magnitude of the shock. In this paper, we refer to a reinforcing feedback loop in the case of amplification of a shock after the feedback loop, i.e. $\Delta x_{i}\left(t_{n}\right)>\Delta x_{i}\left(t_{0}\right)$, and to a balancing feedback loop in the opposite case, e.g. $\Delta x_{i}\left(t_{n}\right)<\Delta x_{i}\left(t_{0}\right)$.

\footnotetext{
${ }^{1}$ Note, that a shock can be considered as a change in any macroeconomic variable describing the institutional sector, but for the sake of simplicity of notations, we use a shock on total assets from now on.
} 
Let us introduce two qualitative definitions of cycles and feedback loops to capture the presence of closed chains of dependencies that may result from the financial contracts. The reason why we need two different definitions is that sometimes the same financial contract can result in different types of dependencies, as a function of market conditions and agents' behavior.

Definition 9. A closed chains of financial dependencies. Let us consider a sequence of sectors $i, j, \ldots$. Let us assume that there is a macroeconomic variable $x$ associated with the each sector in the sequence, and that there is a dependency between the sectors in the aforementioned sequence (e.g. $x_{i j}$ ) in a form of a causal relation between some of these sectors. A closed chain of dependencies of length $n$ is a sequence of sectors $i, i+1, \ldots i+n-1, i+n$, such that there is a causal relation between the variables of each pair of adjacent sectors in the sequence.

Definition 10. Closed chain of financial contracts. A closed chain of financial contracts of length $n$ is a sequence of sectors $i, i+1, \ldots i+n-1, i+n$, such that there is a financial contract between the each pair of adjacent sectors in the sequence.

Definition 11. Reinforcing feedback loop. A closed chain of dependencies is a reinforcing feedback loop if the magnitude $\Delta A_{i}\left(t_{n}\right)$ of the shock at $t_{n}$ is larger than the initial magnitude of the shock i.e. $\Delta A_{i}\left(t_{n}\right)>\Delta A_{i}\left(t_{0}\right)$. The chain is a balancing feedback loop in the opposite case.

Remark 2. Notice that in the above definition, a reinforcing feedback loop does not necessarily lead to an unstable dynamics of the shock. Indeed, the shock series $\Delta A_{i}\left(t_{0}\right), \Delta A_{i}\left(t_{n}\right), \Delta A_{i}\left(t_{2 n}\right), \ldots$ can very well converge to a finite value. The amplification of the shock through the feedback loop: $\Delta A_{i}\left(t_{\infty}\right) / \Delta A_{i}\left(t_{0}\right)$ is larger than one but finite in this case. Notice also that reinforcing feedback loops are also often called positive feedback loops but they are neither positive nor negative in the colloquial sense of the term. For instance, positive feedback loops can be detrimental for the economy if they amplify adverse shocks. 


\subsection{Chains of financial contracts and feedback loops}

In this section, we state some results on the relation between the chains of financial contracts and the feedback loops.

Let us start with the simplest case of a closed chain of e.g. equity holdings in which firm $i+1$ hold equity shares in a firm $i$ etc. Following basic accounting principles, an increase in market value of a firm $i$ leads to an increase in asset values for the next firm $i+1$. By induction, this holds for all other firms in the chain including firm $i$ itself. Whether this result is consistent with a general equilibrium valuation of equity and to what extent in the practice market players take these effect into account are open questions which we do not address here. Our goal is to identify the possible shock transmission channels due to the presence of chain of financial contracts between the firms.

We then consider debt securities that mature at time $T$ in the future and yield either their face value or a value equal to their face value times a recovery rate in case of default of the obligor. We assume that securities are valued today, based on available information and that their valuation is carried out in terms of their expected value at the maturity $T$, depending on the face value of the security and the default probability of the obligor at the maturity (Bardoscia et al., 2016; Barucca et al., 2016).

It is intuitive that in the case that a negative shock occurs on the obligor today (adding up to the prior available information), its default probability goes up and the expected value of its debt security goes down. Therefore, under these assumptions, a closed chain of debt securities in which agent $i+1$ holds debt securities of agent $i$, leads to a reinforcing feedback loop for an initial negative shock because each agent in the closed chain is affected negatively by the adverse shock on the previous one. Notice that, while the expected value of a tradable debt security, i.e. a bond, cannot exceed its face value, it can go up with respect to its previous value if the default of an obligor (i.e. the bond issuer) becomes less likely than before. The same holds for the expected value of a loan. Therefore, a closed chain of debt securities can lead to a reinforcing feedback loop even for a positive shock, with the limitation that the security value cannot exceed the face value. This limitation does not hold for equity holdings. The above considerations can be formalized in the following Propositions 4, 5, 6. In turn, these 
propositions derive from the fact that financial contracts such as equity and debt securities preserve the sign of the shocks propagating from the obligor to the security holder, formalized in Proposition 4

Proposition 4. Shock Transmission and Sign of shocks. Financial contracts such as equity holdings and debt securities strictly preserve the sign of the shocks from the obligor to the security holder.

Proof. Please see Appendix A for the proof.

Proposition 5. Closed chains of equity holdings or debt securities and reinforcing feedback loops. The following closed chains of contracts can lead to a reinforcing feedback loop both in the case of an initial negative or positive shock: i) a closed chain of only equity holdings ii) a closed chain of only debt securities (e.g. both bonds and loans) iii) a closed chain including both equity holdings and debt securities.

Proof. Please see Appendix A for the proof.

Proposition 6. Closed chains of equity and debt securities and balancing feedback loops. A closed chain of contracts of equity or debt securities, either bonds or loans, can not lead to a balancing feedback loop both in the case of an initial negative or positive shock.

Proof. Please see Appendix A for the proof.

Since we exclude from our analysis financial derivatives at this stage, Proposition 6 implies that if we want to find balancing feedback loops in the financial network we need to look at different types of financial dependencies between the institutional sectors, such as those resulting from changes in the exposures between the institutional sectors due to e.g. mechanisms of supply and demand.

\subsection{Shock transmission channels in the financial sectors and sectors of the real economy}

The existence of chains of financial contracts can serve as a ground for shock transmission channels in the financial network. One can highlight two types of shock transmission channels. 
The first type of channel materializes through changes in securities valuation. The simplest case of shock propagation in this case is a shock propagation through equity holdings. The asset of the holder changes in value proportionally to the market value of the issuer's equity changes. Another case originates from valuation adjustments in debt securities along a chain of counterparties. This channel plays out when debt securities are valued in a mark-to-market environment. Table 1 lists examples of shock transmission cases depending on various financial contracts and the type of the shock transmission channel.

The second type of shock propagation channel is a result of changes in investments/savings decisions along a chain of actors connected by financial contracts.

The feedback loops between the financial sectors and sectors of the real economy resulting from financial contracts of equity and debt securities can be identified by exploiting the properties of the adjacency matrix of a network. Indeed, the entries of the n-power of the weighted adjacency matrix of a network gives the sum of the products of the weights along the paths. Hence, the diagonal of $n$-th power of the matrix of financial exposures gives the magnitude of such a sum of products. In this paper, we limit our analysis to paths not longer than five $\biguplus^{2}$, and choose the most important paths including the highest financial exposures in percentage points (see Section 4).

\subsection{Climate policy shocks' transmission channels}

There is a growing discussion around the role of different sets of climate policies to reach the $2^{\circ} \mathrm{C}$ target. Market-based solutions (e.g. a carbon tax, or feed-in tariffs), command-control policies (e.g. an imposed limit to GHG emissions, Lamperti et al., 2016), more recent green macro-prudential regulations (HLEG-Sust-Fin, 2017) and green monetary policies (Monnin and

${ }^{2}$ An empirical analysis for the Euro Area shows that the longer the chain of the financial contracts in the feedback loop, the smaller is the shock amplification in this feedback loop. While analyzing the feedback loops in the Euro Area we found that the shock amplification for the largest (in terms of financial exposures between the sectors) feedback loop of lengths five is less than 1\% for exposure links and less than $12 \%$ for leverage links (see Tables 45, and Section 3.6). Therefore, we limit our analysis to the feedback loops of length no longer than five as further increase of the feedback length leads to an insignificant shock amplification. 
Barkawi, 2015, Monasterolo and Raberto, 2018) are the most debated in the climate-finance policy arena, and, thus, the more likely to be introduced in the near-future (HLEG-Sust-Fin, 2017). In addition, an economic assessment for these policies has already been provided.

We analyze only a limited number of reinforcing feedback loops that can materialize through a re-evaluation of exposures for reasons of space. Indeed, the longer the feedback loop is, the smaller is the impact of an additional exposure to the shock amplification and, thus, the explanatory power of the feedback loop.

The climate policies' feedback loops are analyzed against a baseline of an early-and-gradual implementation of the climate policies when market players are able to smoothly adjust their expectations on prices as the policies phase-in. As a result, no systematic mispricing occurs and the shock propagation through the re-evaluation of contracts is negligible. However, if we consider a scenario of the late-and-sudden introduction of climate policies, market players are not able to fully anticipate price adjustments and that results in systematic mispricing, and shock propagation via financial contracts between the sectors that form feedback loops through which the shock get amplified.

In particular, we focus on two types of feedback loops with respect to the sector where the initial shock originates, i.e. non-financial firms and banks. We start by analyzing how climate policy shocks originated in the non-financial firms affect other sectors, and how they come back to non-financial firms amplified through a reinforcing feedback loop. Similar analysis is performed for the policy shocks affecting first banks, and then propagating to other sectors, including the real economy, and then returning to banks.

Climate policy shocks hitting banks could result from the introduction of unconventional monetary policies, such as green asset purchasing programs (i.e. a green Quantitative Easing $(\mathrm{QE})$ ), or from the introduction of financial regulation of the banking sector such as e.g. differential capital requirements for green loans (i.e. green macroprudential policies). Policy shocks hitting non-financial firms could result, for instance, from the introduction of a carbon tax or other measures to limit carbon emissions that market players did not fully anticipate. The types of policies and policy shocks are listed in Table 2

For each type of climate policy, either affecting banks or non-financial firms, we perform a 
policy evaluation. We consider i) policy's effect on the institutional sectors, and ii) the feedback loops within the institutional sectors. The empirical analysis of the magnitudes of financial exposures between institutional sectors of the Euro Area allows us to qualitatively estimate the effects of climate policies and to point out specific feedback loops that could emerge in the Euro Area economy. This information, despite being still missing from the policy debate, is key to assess the overall effect of the climate policies during the climate policy implementation and evaluation phases.

\subsection{Climate policy shocks' transmission through the macro-network of financial interdependen-} cies

In the following section, we discuss the relation between the magnitude of the shock amplification through a feedback loop considering two types of potential shock transmission: i) through exposure amplification, and ii) through leverage amplification. We also provide analytical formulas for the computation of the policy shock amplification, which is crucial for the assessment of the climate policy shock transmission.

\subsubsection{Financial shocks transmission through exposures between the institutional sectors.}

The mechanism of the shock propagation and accumulation can be described as follows. Let us consider a simple scenario of two institutional sectors with assets $A_{i}$ and $A_{j}$, and their mutual exposures $A_{i j}$ and $A_{j i}$, respectively. Then, in case of an initial shock $\Delta A_{i}\left(t_{0}\right)$ to a sector $i$ (where the shock - $\Delta A_{i}\left(t_{0}\right)$ - shows changes in assets of the sector $i$ ), in the first round of shock propagation, a sector $j$, will have a shock:

$$
\Delta A_{j}\left(t_{1}\right)=A_{j i} \cdot \frac{\Delta A_{i}\left(t_{0}\right)}{A_{i}},
$$

In the second round, the shock will come back to the sector $i$, and the resulted shock of this sector will be:

$$
\Delta A_{i}\left(t_{2}\right)=A_{i j} \cdot \frac{\Delta A_{j}\left(t_{1}\right)}{A_{j}}=\frac{A_{i j}}{A_{j}} \cdot A_{i j} \cdot \frac{\Delta A_{i}\left(t_{0}\right)}{A_{i}}=\Delta A_{i}\left(t_{0}\right) \cdot w_{i j} \cdot w_{j i} .
$$

where $w_{i j}$ is the relative exposure of the sector $i$ to the sector $j$ (defined as in equation 6). In the more general case of a shock reverberation through the feedback loop of length $n$, the shock 
hitting a sector $i$ can be expressed through this sector's shock in the previous round using this formula:

$$
\Delta A_{i}\left(t_{n}\right)=\Delta A_{i}\left(t_{0}\right) \cdot\left(w_{i j} \cdot w_{j m} \cdot \ldots \cdot w_{n i}\right)
$$

where $\Delta A_{i}\left(t_{n}\right)$ is a shock hitting a sector $i$ after one reverberation through the feedback loop of length $n, \Delta A_{i}\left(t_{0}\right)$ is an initial shock hitting a sector $i$, and $w_{j m} \cdot \ldots \cdot w_{n i}$ are normalized by total assets exposures between the sectors along the chain of financial contracts.

The shock amplification described by equation 9 could occur when one considers holdings of equity shares, as the effect of the shock on the equity holdings can be viewed as proportional to the shock in both cases of positive and negative shock. In contrast, a bond or a loan can not pay more than their nominal value. However, conditional upon a positive shock on the creditworthiness of the issuer, the expected value of the loan can increase if it was lower than nominal value.

Definition 12. We define as number of reverberations in the feedback loop the number of times that an initial shock returns to the sector $i$ where it originated.

Let us consider the simple case of a feedback loop of length two between two sectors. Then, in the case of an infinite number of reverberations through the feedback loop, the magnitude of the cumulative shock on the sector $i$ is:

$$
\begin{gathered}
\Delta A_{i}(\infty)=\Delta A_{i}\left(t_{0}\right)+\Delta A_{i}\left(t_{2}\right)+\Delta A_{i}\left(t_{2 n}\right)+\ldots=\sum_{n=0}^{\infty} \Delta A_{i}\left(t_{2 n}\right)=\Delta A_{i}\left(t_{0}\right)+\Delta A_{i}\left(t_{0}\right) w_{i j} w_{j i}+ \\
\Delta A_{i}\left(t_{0}\right)\left(w_{i j} w_{j i}\right)^{2}+\Delta A_{i}\left(t_{0}\right)\left(w_{i j} w_{j i}\right)^{3}+\ldots=\Delta A_{i}\left(t_{1}\right) \sum_{n=0}^{\infty}\left(w_{i j} w_{j i}\right)^{k}=\Delta A_{i}\left(t_{0}\right) \frac{1}{1-w_{i j} w_{j i}} .
\end{gathered}
$$

We can generalize the notion to the following definition.

Definition 13. Consider an infinite number of shock reverberations through a feedback loop of length $n$ starting from sector $i$. The feedback loop exposure amplification is defined as the ratio of the cumulative shock over the initial shock to the sector $i$ :

$$
M_{i}=\frac{\Delta A_{i}(\infty)}{\Delta A_{i}\left(t_{0}\right)}=\sum_{k=0}^{\infty}\left(w_{i j} \cdot w_{j m} \cdot \ldots \cdot w_{n i}\right)^{k}=\frac{1}{1-w_{i j} \cdot w_{j m} \cdot \ldots \cdot w_{n i}} .
$$


Notice that the sum in the above equation is always finite because the exposures $w_{i j}, \ldots w_{m i}$ are all smaller than one.

\subsubsection{Financial shocks transmission through leverage between the institutional sectors.}

When one takes into account i) the recovery rate of assets of a market player after the shock (Battiston et al., 2016a; D'Errico et al., 2017), ii) the balance sheet identities of individual sectors, iii) an assumption of a simple rule for shocks' transfer from borrowers to lenders (Bardoscia et al. 2015), it emerges that the shock propagation from one sector to another is not proportional to the exposure between the sectors but to their leverage, i.e. the ratio of the shock to the sector's equity, calculated as the difference between assets and liabilities. In particular, financial shocks could be transmitted through the net leverage matrix.

Definition 14. A net leverage matrix is defined (similar to Battiston et al. 2016a) as:

$$
\lambda_{i j}=\frac{A_{i j}(1-r)}{E_{i}}
$$

where $A_{i j}$ is the exposure of an institutional sector $i$ to a sector $j, E_{i}$ is equity of a sector $i$ (computed as a difference between assets and liabilities of the sector), and $r$ is a recovery coefficient rate or recovery rate, i.e. a portion of assets of the institutional sector $i$ that is recovered after a shock due to assets re-evaluation.

Then, similarly to equation 7 , in case of an initial shock $\Delta A_{i}\left(t_{0}\right)$ to a sector $i$ (where the shock $\Delta A_{i}\left(t_{0}\right)$ shows changes in assets of the sector $\left.i\right)$, in the first round of shock propagation, a sector $j$, will have a shock proportional to the leverage:

$$
\Delta A_{j}\left(t_{1}\right)=\lambda_{j i} \cdot \Delta A_{i}\left(t_{0}\right)
$$

Therefore, in case of conditions i)-iii) (considering a shock transmission through the leverage matrix), in the simple case of a feedback loop between the two sectors, equation 9 can be modified as:

$$
\Delta A_{i}(\infty)=\Delta A_{i}\left(t_{0}\right) \sum_{k=0}^{\infty}\left(\lambda_{i j} \lambda_{j i}\right)^{k},
$$

where $\Delta A_{i}\left(t_{0}\right)$ is an initial shock to the sector $i$, and $\lambda_{i j}$ is defined as in equation 12 
Similarly to equation 11, we can formulate the following definition.

Definition 15. Consider an infinite number of shock reverberations through a feedback loop of length $n$ starting from sector $i$. The feedback loop leverage amplification is defined as the ratio of the cumulative shock over the initial shock to the sector $i$ :

$$
M_{i}=\frac{\Delta A_{i}(\infty)}{\Delta A_{i}\left(t_{0}\right)}=\sum_{k=0}^{\infty}\left(\lambda_{i j} \cdot \lambda_{j m} \cdot \ldots \cdot \lambda_{n i}\right)^{k},
$$

where $\Delta A_{i}(\infty)$ is a shock after the feedback loop amplification, and $\Delta A_{i}\left(t_{0}\right)$ is an initial shock on the sector $i$.

Notice also that if the recovery rate is one, $r=1$, (i.e. a sector recovers all assets after a shock), then the amplification is one, $M_{i}=1$ meaning that there is no shock amplification through the feedback loops.

However, the sum in the above equation may be unbounded because the leverage components $\lambda_{i j}, \ldots \lambda_{n i}$ can be larger than one (i.e. when a financial actor invests in the contracts with another one an amount larger than its own equity). In this case, we consider the value of the amplification after only one reverberation, defined as:

$$
M_{i}^{1}=1+\lambda_{i j} \cdot \ldots \cdot \lambda_{n i}
$$

In the simple case of a feedback loop of length two with equal exposure $A_{i j}=A_{j i}$ between the two sectors with the same value of equity $E_{i}=E_{j}$, and recovery rate $r$ the mathematical expression for the shock amplification ratio transforms into the following equation:

$$
M_{i} \sim 1+\left(\frac{A_{i j}(1-r)}{E_{i}}\right)^{2}
$$

The definition of a feedback loop leverage amplification can be also extended to a more general case.

Definition 16. A feedback loop leverage amplification $M_{i}$ for all loops for a given sector $i$ is defined as a sum of products of leverage matrix (equation 12 ) along all cycles of all length (for 
all feedback loops $L$ ):

$$
M_{i}=\sum_{s=0, n \in L}^{\infty}\left(\lambda_{i j} \cdot \lambda_{j m} \cdot \ldots \cdot \lambda_{n i}\right)^{s}=1+\lambda_{i j} \cdot \lambda_{j i}+\ldots
$$

According to Bardoscia et al. (2017), the existence of multiple unstable closed chains of contracts implies unstable distress propagation dynamics. Therefore, $M_{i}>1$ implies shock propagation dynamics (applicable to both positive and negative shocks) through the feedback loops of financial contracts.

\section{Empirical Results}

In this section, we illustrate the analytical results obtained in Section 3 on an empirical dataset of financial exposures between the institutional sectors in the Euro Area. First, we identify the main feedback loops in the Euro Area financial macro-network (see Tables 4 and 5. Second, we apply our methodology from Section 3 to estimate the climate policy shock amplification through the shock transmission mechanism via re-evaluation of financial contracts (e.g. equity). Finally, we also discuss some possible shock transmission mechanisms related to changes in investment decisions of market players regarding the size of existing financial exposures.

\subsection{Data on institutional sectors and financial exposures among sectors}

We consider the institutional sectors defined as according to the ECB classification (see Appendix B) as follows: Non-Financial Corporations (NFC, or non-financial firms), Banks or Monetary Financial Institutions (MFI, or banks), Non-MMF Investment Funds (IF), Other Financial Institutions (OFI), Insurance Corporations and Pension Funds (IESPF), General Governments (Gov), Households (HH).

We collected data from various data sets including bilateral financial exposures between institutional sectors of the Euro Area for eight types of financial instruments (listed equity, investment funds shares, short-term bonds, long-term bonds, short-term loans, long-term loans, deposits, insurance and pension schemes guarantees) and information on total financial assets and liabilities of the institutional sectors provided by the European Central Bank (ECB) Data 


\footnotetext{
$\sqrt[3]{\text { http://sdw.ecb.europa.eu/ }}$
}

Warehouse ${ }^{3}$. In our analysis, we aggregate data on mutual exposures through short-term loans, long-term loans and deposits under "loans". Similarly, exposures through short-term (i.e. with maturity less than a year) and long-term (i.e. with maturity more than a year) bond holdings are aggregated under "bonds"; exposures through listed shares, unlisted shares and investment fund shares are aggregated under " equity"; exposures through insurance\&pension schemes guarantees form a separate category. This aggregation allows to combine into one group instruments for which the effect of the shock to a counterparty resulting in the re-evaluation of the asset of an institutional sector is similar. This means that equity shares' holdings are evaluated differently from the loan holdings. While the ECB provides data on mutual exposures of institutional sectors through listed shares and investment fund shares, unfortunately, it does not provide this information for the unlisted equity, which corresponds to $62 \%$ of the total equity holdings in the Euro Area. However, the ECB provides information on total holdings of the unlisted shares by each institutional sector. Most of this unlisted equity is represented by assets of non-financial corporations ( $41 \%$ of all equity shares of this sector), other financial institutions (46\%) and government (26\%), while for remaining institutional sectors the holdings of unlisted equity is less than $6 \%$ (with the exception of households - 14\%) (see Table 3 for details of the assets of the Euro Area institutional sectors). Therefore, due to the lack of available data on mutual exposures between the institutional sectors through unlisted equity shares, we decide to take into account available data on unlisted equity shares' holdings by each institutional sector. In order to reconstruct the bilateral exposures through unlisted equity between the institutional sectors, we assume the same percentage of allocation for unlisted equity shares from each institutional sector as for the listed equity shares of this institutional sector.

Taking into account the collected bilateral data on mutual exposures between the sectors, the reconstructed data for mutual exposure through unlisted equity and the data on total financial assets of the institutional sectors, we reconstruct the multilayer weighted financial network. Each layer corresponds to one of the four financial instruments: equity shares, bond holdings, loans holdings and holdings of insurance\&pension fund guarantees. The weighted 
link in the macro-network of institutional sectors is a total amount of monetary exposure between the institutional sectors through a chosen financial instrument (equity, bonds, loans and insurance\&pension schemes guarantees) weighted by the total assets of the institutional sector for which the exposure is calculated. The link has the direction of the exposure: from an institutional sector holding an asset to an institutional sector issuing the asset.

The ECB Data Warehouse provides data on mutual exposures between the institutional sectors of the Euro Area, as well as the total value of financial contracts through all instruments which Euro Area institutional sectors have with the rest of the world (non-Euro Area). However, the information about the institutional allocation of the exposures to and from the rest of the world is not identified. In order to overcome this limit, we reconstruct the financial exposure allocation outside of the Euro Area in terms of allocation of equity shares using a similar allocation to that between the institutional sectors as within Euro Area. Despite this might be considered as a strong assumption, it does not change the main channels of exposure between the institutional sectors as most of the assets of the Euro Area institutional sectors lie within Euro Area, except for equity and bonds holdings of the Euro Area investment funds to nonEuro Area. Taking into account that the majority of the equity shares is issued by non-financial firms in the Euro Area, it is reasonable to assume the same situation could characterize the non-Euro Area as well. Therefore, we use the percentage of issuance of equity shares by Euro Area institutional sectors to allocate the exposure of the Euro Area investment funds outside the Euro Area. For allocation of bonds and loans holdings, we used the same assumption. As in case of equity, this assumption only affected the investment funds of the Euro Area through bonds, as the rest of the institutional sectors of the Euro Area have their assets within Euro Area. The data on financial exposures among the institutional sectors through equity, bonds, loans and insurance and pension schemes guarantees used in the study correspond to outstanding amounts for the fourth quarter of 2015, due to the fact that corporate financial reporting is usually for the previous fiscal year and data analysis and consolidation takes some time.

\subsection{Shock propagation due to re-evaluation of financial contracts among institutional sectors.}


In the following, we consider as a baseline an early-and-gradual implementation of the climate policies discussed in Section 3.5. In the baseline scenario, market players are able to smoothly adjust their expectations on prices as the policies phase-in. Thus, no systematic mispricing occurs and as result the shock propagation through the re-evaluation of contracts is negligible.

Against such a baseline, we consider a scenario of the late-and-sudden introduction of the climate policies. In this scenario, market players are not able to fully anticipate price adjustments and therefore there is potential for systematic mispricing and shock propagation via financial contracts. Accordingly, we analyze the macro-network of financial exposures between the institutional sectors as in Q4, 2015 4. Then, we apply the methodology described in Section 3.6 to analyze how an initial climate policy shock on sector $i$ (e.g. banks), with magnitude $\Delta A_{i}(0)$, gets amplified through a selected feedback loop (e.g. Banks $\rightarrow$ Banks). We then compare the results of the two shock transmission mechanisms described in Sections 3.6.1 and 3.6.2 i) shock transmission through financial exposures between the institutional sectors, and ii) shock transmission through leverage between the institutional sectors.

For each of the considered feedback loops we compute: i) the exposure amplification (see eq. 11), and ii) the leverage amplification (see eq. 15). The latter represents the magnitude of the climate policy shock amplification, e.g. by how much the initial climate policy shock gets amplified after a) one reverberation $\left(M_{i}^{1}\right)$ and b) an infinite number of reverberations $\left(M_{i}\right)$. The results are presented in Tables 4, 5 .

We start with a scenario of a policy-induced shock affecting in the first place the banking sector directly (see loops 1-6 from Table 4). Visualizations of some of the feedback loops involving banks can be found in Figures $1 / 2[3$.

Based on the methodology described in Section 3, the shortest closed chain we can identify is the feedback loop of the sector Banks onto itself: Banks $\rightarrow$ Banks. As discussed in Section 3 , we cannot assume that assets and liabilities can be netted out in the aggregate. In particular, financial exposures within the banking sector have been identified in the financial contagion lit-

\footnotetext{
${ }^{4}$ http://sdw.ecb.europa.eu/
} 
erature as a channel of shocks' amplification that can be responsible for increasing the impact of an initial shock up to a factor two (related to the interbank leverage, see Battiston et al. 2016c). Using the described methodology, we compute the feedback loop exposure amplification and the feedback loop leverage amplification of a climate policy shock for the cases listed in Table 4. Considering exposures through four financial instruments together (equity, bonds and loans, insurance\&pension schemes guarantees), we find an exposure amplification of 1.4 (see column 4 of Table 4). We also find a leverage amplification $M_{i}$ that is unbounded (in the extreme case of $r=0$ ), meaning that in mathematical terms a shock would get infinitely amplified through this feedback loop. In practice, of course, many factors intervene to bound the shock amplification. In this case, a more relevant estimate is provided by the amplification after one reverberation, $M_{i}^{1}$, defined in Section 3.6 .2 , which yields a value of 3.7 .

Similarly, we consider a scenario when a climate policy shock affects initially the nonfinancial firms. The most important feedback loops in this scenario are analyzed in Table 5. Visualizations of some of the feedback loops involving non-financial firms can be found in Figures 4 and 5. We find that in case of climate policy shocks affecting firms (e.g. limits on carbon emissions, see row 2, Table 5), a feedback loop Firms $\rightarrow$ Banks $\rightarrow$ Firms can amplify the original climate policy shock by 2.2 times (considering four instruments combined), while a self-loop Firms $\rightarrow$ Firms yields an unbounded leverage amplification. The corresponding value of $M_{i}^{1}$ (after one reverberation) is 2.6 .

For all considered feedback loops starting from both banks and firms, we have also analyzed the dependence of the shock amplification on the Loss-given-default, defined as $(1-r)$, where $r$ is the recovery rate, see Figure 6 .

The values of a feedback loop leverage amplification from column 4 of Tables 4 and 5 can be found from Figure 6 taking into account the recovery rate equal to 0 (Loss given default equal to 1$)$.

\subsection{Shock propagation due to changes in the investment decisions of institutional sectors}

A simple example of climate policy shock propagation through the institutional sectors' investment decisions can be illustrated on a feedback loop of length two involving Banks and 
Households: Banks $\rightarrow$ Households $\rightarrow$ Banks (see Figure 1). We can consider the situation of a positive shock on banks' assets, for instance due to reduced capital requirements for "green" mortgages (i.e. mortgages for retrofitted, low-carbon housing facilities), see Table 4 . Banks respond by increasing their lending for green mortgages, under the condition that households were previously credit-constrained on green mortgages and that they seek to increase their borrowing. The increase of green mortgages induces an increase in the value of green realestate, which would then feed back into higher demand for loans for green mortgages. In this case, we can identify a reinforcing feedback loop starting from banks and returning to banks. A similar reasoning holds in the case of a negative shock on banks' assets due to increased capital requirements for loans to "brown" mortgages (i.e. mortgages to not-retrofitted, high-carbon housing) as a result of the introduction of green macroprudential regulations (Table 4 .

A second example of a feedback loop of length two is Banks $\rightarrow$ Non-financial firms $\rightarrow$ Banks (see Figure 2). We can consider the situation of a positive shock on banks' assets, for instance, induced by a green QE on the subset of banks with large green assets, see Table 4. If banks' liabilities remain unchanged, this shock also implies an increase in banks' equity level. If banks have target leverage (Adrian and Shin, 2009; Tasca and Battiston, 2016; Monasterolo and Raberto, 2018), then they would increase their lending to non-financial firms (under the condition that firms were previously credit-constrained and that they seek to increase their borrowing). Assuming that firms use their increased borrowing to invest in productive capital with positive effects on their performance, this would lead on average to higher creditworthiness of the firms. As a result, the mark-to-market valuation of the loans granted by banks to the firms would increase on the banks' asset side. This would lead in turn to a positive shock to the banks' asset side of the balance sheet closing a reinforcing feedback loop.

A similar reasoning holds for the case of a negative shock on some banks' assets, for instance induced by tighter capital requirements on the subset of banks with large brown assets (Table 4 ). If banks' liabilities remain unchanged, this shock would imply also a decrease in banks' equity level. If banks have target leverage, then they would decrease their exposure to brown nonfinancial firms. In this case, the transmission channel is a change in investment decision along the loan linkage (see Table 3. Let us assume that a lower supply of funding would negatively 
affect firms' creditworthiness. Thus, the mark-to-market valuation of the loans granted to the brown firms decreases the banks' asset side. This chain of effects illustrates a negative shock transmission through the reinforcing feedback loop Banks $\rightarrow$ Non-financial firms $\rightarrow$ Banks. Important to note that in the last step, the transmission channel is represented by the securities valuation of the loans themselves, but we could also consider the decrease of the level of deposits that non-financial firms hold in banks that would decrease the liquidity of the banks.

\section{Conclusions}

The introduction of climate policies to achieve the global climate and sustainability targets should consider the impact of the same policies on the financial sector in order to make finance part of the global sustainability solution. However, traditional economic models used for policy evaluation do not include a financial sector or represent it in a very simplistic way, neglecting financial interconnectedness and the transmission channels between the actors of the financial sector and those of the real economy. In addition, they focus their analysis of the policy effects on the institutional sector that the policy would target. This means that they neglect the possible feedback loops between sectors thus underestimating the overall - and sometimes unintended - effect of the policy on interconnected actors and sectors. Finally, it has been highlighted that the assumptions of agents' rationality and market clearing prices cannot hold in the case of technological and climate policy shocks that characterize the low-carbon transition. Indeed, in case of systematic mispricing of assets (e.g. used as collateral of contracts, or that matter for calculation of loss-given-default), the recovery rate on contract values can be lower than one, thus implying counterparty risk. In this case, closed chains of collateralized financial contracts give rise to feedback loops that amplify negative shocks resulting from late-and-sudden climate policies.

In this paper, we develop a methodology that relies on multilayer financial-real economy networks to provide a comprehensive assessment of the impact of climate policies' shocks on the financial sector and the real economy, thus overcoming the limits of current approaches. Our methodology accounts for the amplification of climate policy shocks due to interlinkages among institutional sectors, and, in particular, due to feedback loops emerging in closed chains 
of relations among institutional sectors.

We focus on the shock transmission channel consisting of changes in the valuation of equity and debt securities conditional upon a shock on the asset side of the security issuer. We show that in this context a closed chain of common contracts (e.g. equity or debt securities) cannot lead to a balancing feedback loop. We also show that, under mild conditions, the distress propagation through financial contracts between the firms in different sectors can be aggregated and represented as a distress propagation through the macro-network of financial exposures between the sectors. In order to quantify the effects, we define two measures for the shock amplification assessment: feedback loop exposure amplification and feedback loop leverage amplification.

We then apply our methodology to an empirical dataset of the Euro Area economy in the context of climate policies. By building on various data sources we reconstruct a macro-network of financial interdependencies in the Euro Area and identify the main feedback loops of financial interdependencies for the Euro Area. We analyze how climate policy shocks originated in the non-financial firms can affect other sectors, and how they come back to non-financial firms amplified through a reinforcing feedback loop. A similar analysis is performed for the policy shocks affecting first banks, then propagating to other sectors, including the real economy, and then returning to banks. We also discuss how shocks (positive or negative) on banks and non-financial firms could materialize as result of the introduction of a set of possible climate policies. Then, we compute the shock amplification in various scenarios including the case of the banking sector affected by green monetary policies (e.g. a green QE), or by green macroprudential regulation, and the real economy affected through policies such as a "carbon tax".

We find that the magnitude of the amplification through the feedback loops can be substantial. The specific values of the amplification are critically dependent on recovery rate $(r)$, which in turn is not easy to estimate and depends on policy action (e.g. asset purchasing programs). However, one of the insights of this analysis is obtained from the comparison of the amplification of different feedback loops (for given values of $r$ involved). A larger feedback loop amplification implies a stronger ability of this feedback loop to amplify shocks. These results are important to understand the relevance of the relation between climate policies and finance, and the po- 
tential systemic effects of climate policies on the stability of the financial sector and on the performance of the real economy. Thus, our methodology contributes to inform the design and implementation of climate policies that are effective and at the same time sustainable for the financial sector. Indeed, our analysis shows that a small positive/negative climate policy shock hitting the banking system could lead to a great amplification in the banks-households chain, and, eventually, result in great gains/losses for the banking system, with positive/negative implications for the real economy in case of the late-and-sudden introduction of the climate policies.

\section{Acknowledgements}

We are grateful to Mauro Napoletano (OFCE), Olga Briukhova (UZH) and Alan Roncoroni $(\mathrm{UZH})$ for useful discussions on earlier versions of this paper, as well as to the participants of the EAEPE 2017 Conference for their comments. V.S. and S.B. acknowledges the support from the of the EU H2020 project ISIGrowth project (grant agreement no. 649186) of European Union Horizon 2020 Research and Innovation action. S.B. acknowledges financial support from the Swiss National Fund Professorship grant no. PP00P1-144689. All the authors acknowledge the support of the European Project and the EU Future and Emerging Technologies (FET) project DOLFINS (grant agreement no. 640772). S.B. acknowledges the financial support of the Swiss National Science Foundation Professorship (grant no. PP00P1-144689). All the authors thank the anonymous reviewers for their useful helpful and detailed comments on the earlier version of the manuscript.

\section{References}

Adrian, T., Shin, H. S., 2009. Money, liquidity, and monetary policy. American Economic Review 99 (2), 600-605.

Annicchiarico, B., Di Dio, F., 2016. GHG Emissions Control and Monetary Policy. Environmental and Resource Economics, 1-29. 
$0-84959331081\{\&\}$ partnerID=tZOtx3y1

Balint, T., Lamperti, F., Mandel, A., Napoletano, M., Roventini, A., Sapio, A., 2017. Complexity and the economics of climate change: a survey and a look forward. Ecological Economics $138,252-265$.

Bardoscia, M., Battiston, S., Caccioli, F., Caldarelli, G., jan 2015. DebtRank: A microscopic foundation for shock propagation. PLoS ONE 10 (6), e0134888.

URLhttp://journals.plos.org/plosone/article?id=10.1371/journal.pone.0130406

Bardoscia, M., Battiston, S., Caccioli, F., Caldarelli, G., 2017. Pathways towards instability in financial networks. Nature Communications 8, 14416.

URL http://arxiv .org/abs/1602.05883

Bardoscia, M., Caccioli, F., Perotti, J. I., Vivaldo, G., Caldarelli, G., 2016. Distress propagation in complex networks: The case of non-linear DebtRank. PLoS ONE 11 (10), 1-12.

Barkawi, A., 2017. Financial Times - alphaville post 2017/05/18/2189013 "Why monetary policy should go green".

URL https://ftalphaville.ft.com/2017/05/18/2189013/ guest-post-why-monetary-policy-should-go-green/

Barucca, P., Bardoscia, M., Caccioli, F., D'Errico, M., Visentin, G., Battiston, S., Caldarelli, G., 2016. Network Valuation in Financial Systems. SSRN 1606.05164, 1-16.

URL http: //arxiv .org/abs/1606.05164

Battiston, S., Caldarelli, G., D'errico, M., Gurciullo, S., 2016a. Leveraging the network : a stress-test framework based on DebtRank. Statistics and Risk Modeling 33 (3-4), 1-33.

URL http: //papers.ssrn.com/sol3/papers.cfm?abstract\{_\}id=2571218

Battiston, S., Caldarelli, G., May, R., Roukny, T., Stiglitz, J. E., 2016b. The Price of Complexity in Financial Networks. PNAS 113 (36), 10031-10036. 
Battiston, S., D'Errico, M., Gurciullo, S., 2016c. DebtRank and the network of leverage. Journal of Alternative Investments 18 (4), 68-81.

Battiston, S., Mandel, A., Monasterolo, I., Schutze, F., Visentin, G., apr 2017. A climate stresstest of the financial system. Nature Clim. Change 7 (4), 283-288.

URL http://dx.doi.org/10.1038/nclimate3255

Blanchard, O., 2018. On the future of macroeconomic models. Oxford Review of Economic Policy 34 (1-2), 43-54.

Böhringer, C., Löschel, A., 2006. Computable general equilibrium models for sustainability impact assessment: Status quo and prospects. Ecological Economics 60, 49-64.

Bosetti, V., Carraro, C., Galeotti, M., Massetti, E., Tavoni, M., 2006. Witch a world induced technical change hybrid model. The Energy Journal, 13-37.

Caldecott, B., McDaniels, J., 2014. UNEP-Inquiry: Financial Dynamics of the Environment: Risks, Impacts, and Barriers to Resilience. Tech. rep., UNEP.

Calvin, K., Wise, M., Clarke, L., Edmonds, J., Kyle, P., Luckow, P., Thomson, A., 2013. Implications of simultaneously mitigating and adapting to climate change: initial experiments using GCAM. Climatic Change 117 (3), 545-560.

Campiglio, E., 2016. Beyond carbon pricing: The role of banking and monetary policy in financing the transition to a low-carbon economy. Ecological Economics 121, 220-230.

Carney, M., 2015. "Breaking the Tragedy of the Horizon - Climate Change and Financial Stability. " Speech given at Lloyd's of London by the Governor of the Bank of England. Tech. rep.

Castrén, O., Rancan, M., sep 2014. Macro-Networks: An application to euro area financial accounts. Journal of Banking \& Finance 46, 43-58. URL http://www.sciencedirect.com/science/article/pii/S0378426614001538 
Cimini, G., Squartini, T., Garlaschelli, D., Gabrielli, A., Garlaschelli, D., 2015. Systemic risk analysis in reconstructed economic and financial networks. Scientitic Reports 5.

Coibion, O., Gorodnichenko, Y., Kueng, L., Silvia, J., 2017. Innocent Bystanders? Monetary policy and inequality. Journal of Monetary Economics 88, 70-89.

CPLC, 2017. CPLC, "Report of the High-Level Commission on Carbon Prices", 2017. Tech. rep., Carbon Pricing Leadership Coalition.

Dafermos, Y., Nikolaidi, M., Galanis, G., jan 2017. A stock-flow-fund ecological macroeconomic model. Ecological Economics 131, 191-207.

URL http://dx.doi.org/10.1016/j.ecolecon.2016.08.013

D'Errico, M., Battiston, S., Peltonen, T., Scheicher, M., may 2017. How does risk flow in the credit default swap market? Journal of Financial Stability.

URL http://wWw.sciencedirect.com/science/article/pii/S157230891730339X

Dietz, S., Bower, A., Dixon, C., Gradwell, P., 2016. Climate value at risk of global financial assets. Nature Climate Change, Letter 6, 676-679.

EC, 2015. European Commission Report "An EU Action Plan for the Circular Economy". Tech. rep.

ESRB, 2016. ESRB Advisory Scientific Committee - Report, "Too Late, Too Sudden: Transition to a Low-Carbon Economy and Systemic Risk.". Tech. rep.

Farmer, J. D., Hepburn, C., Mealy, P., Teytelboym, A., 2015. A third wave in the economics of climate change. Environmental and Resource Economics 62 (2), 329-357.

Golosov, M., Hassler, J., Krusell, P., Tsyvinski, A., 2014. Optimal taxes on fossil fuel in general equilibrium. Econometrica 82 (1), 41-88.

Haldane, A. G., Turrell, A. E., 2018. An interdisciplinary model for macroeconomics. Oxford Review of Economic Policy 34 (1-2), 219-251. 
HLEG-Sust-Fin, 2017. High-Level Expert Group Sustainable Finance "Financing a Sustainable European Economy“, Interim report. Tech. rep.

HLEG-Sust-Fin, 2018. High-Level Expert Group Sustainable Finance "Financing a Sustainable European Economy“, Final Report. Tech. Rep. January.

IPCC, 2014. IPCC Climate Change 2014 Synthesis Report. Contribution of Working Groups I, II and III to the Fifth Assessment Report of the Intergovernmental Panel on Climate Change. Tech. rep.

Jakab, Z., Kumhof, M., 2014. Models of banking: loanable funds or loans that create funds? ssrn n.2474759.

Kirman, A. P., 1992. Whom or what does the representative individual represent? Journal of economic perspectives 6 (2), 117-136.

Kriegler, E., Tavoni, M., Aboumahboub, T., Luderer, G., Calvin, K., DeMaere, G., Krey, V., Riahi, K., Rösler, H., Schaeffer, M., Others, 2013. What does the 2 C target imply for a global climate agreement in 2020? The LIMITS study on Durban Platform scenarios. Climate Change Economics 4 (04), 1340008.

Lamperti, F., Dosi, G., Napoletano, M., Roventini, A., Sapio, A., 2017. Faraway, so close: coupled climate and economic dynamics in an agent-based integrated assessment model. URL https : //ssrn. com/abstract=2944328

Lamperti, F., Napoletano, M., Roventini, A., 2016. Preventing Environmental Disasters: Market-Based vs. Command-and-Control Policies.

Leaton, J., 2012. Unburnable Carbon - Are the World's Financial Markets Carrying a Carbon Bubble. Carbon Tracker Initiative.

Markose, S. M., Giansante, S., Rais Shaghaghi, A., 2017. A systemic risk assessment of OTC derivatives reforms and skin? in? the? game for CCPs. Financial Stability Review 21, $111-126$. 
Maxton, G., Randers, J., 2016. Reinventing Prosperity: Managing Economic Growth to Reduce Unemployment, Inequality and Climate Change. Greystone books.

McLeay, M., Radia, A., Thomas, R., 2014. Money Creation in the Modern Economy. Bank of England Quarterly Bulletin (Q1), 1-14.

URL http://www . bankofengland .co.uk/publications/Documents/quarterlybulletin/ 2014/qb14q1prereleasemoneycreation.pdf $\{\%\} 5$ Cnpapers2://publication/uuid/ 3703BD2D-E2A7-43A1-86EE-3CE1BEB67A2E

Meadows, D. H., 2008. Thinking in systems: A primer. chelsea green publishing.

Mercure, J., Pollitt, H., Bassi, A., Viñuales, J., 2016. Modelling complex systems of heterogeneous agents to better design sustainability transitions policy. Global Environmental Change. URL http://www.sciencedirect.com/science/article/pii/S0959378016300139

Monasterolo, I., Battiston, S., Janetos, A., Zheng, Z., 2017. Vulnerable yet relevant: the two dimensions of climate-related financial disclosure. Climatic Change 145 (3-4), 495-507.

Monasterolo, I., Raberto, M., 2018. The EIRIN Flow-of-funds Behavioural Model of Green Fiscal Policies and Green Sovereign Bonds. Ecological Economics 144, 228-243.

Monnin, P., Barkawi, A., 2015. UNEP Report "Monetary Policy and Sustainability. The Case of Bangladesh" in IISD and DRC, Greening China's financial system. Tech. rep., Council on Economic Policies.

Nordhaus, W. D., 1993. Rolling the "DICE": an optimal transition path for controlling greenhouse gases. Resource and Energy Economics 15 (1), 27-50.

Nordhaus, W. D., 2016. Projections and uncertainties about climate change in an era of minimal climate policies. Tech. rep., National Bureau of Economic Research.

Palley, T., 2016. Financialization: the economics of finance capital domination. Springer. 
Ponta, L., Raberto, M., Teglio, A., Cincotti, S., 2016. An agent-based stock-flow consistent model of the sustainable transition in the energy sector.

URL https://www.dhs.gov/energy-sector

Revesz, R. L., Howard, P. H., Arrow, K., Goulder, L. H., Kopp, R. E., Livermore, M. A., Oppenheimer, M., Sterner, T., 2014. Global warming: Improve economic models of climate change. Nature 508 (7495), 173-175.

Rezai, A., Stagl, S., 2016. Ecological macroeconomics: Introduction and review. Ecological Economics 121, 181-185.

Romer, P., 2016. The trouble with macroeconomics. The American Economist forthcomin.

Saiki, A., Frost, J., 2014. Does unconventional monetary policy affect inequality? Evidence from Japan. Applied Economics 46 (36), 4445-4454.

Sterman, J. D., 2000. Business dynamics: Systems thinking and modeling for a complex world. URL http://wWw. lavoisier.fr/notice/frJWOAR6SA23WL00.html

Sterman, J. D., 2002. All models are wrong: Reflections on becoming a systems scientist. System Dynamics Review 18 (4), 501-531.

Stiglitz, J. E., 2018. Where modern macroeconomics went wrong. Oxford Review of Economic Policy 34 (1-2), 70-106.

Tasca, P., Battiston, S., 2016. Market Procyclicality and Systemic Risk. Quantitative Finance. URL http://www .tandfonline.com/doi/abs/10.1080/14697688.2015.1123817

Visentin, G., D’Errico, M., Battiston, S., 2016. Rethinking Financial Contagion. working paper ssrn 2831143.

Volz, U., 2017. UNEP Inquiry Report "On the role of central banks in enhancing green finance". Tech. rep. 
Wolf, S., Schütze, F., Jaeger, C. C., 2016. Balance or synergies between environment and economy - a note on model structures. Sustainability 8 (8), 761.

Wray, L. R., 2015. Modern money theory: A primer on macroeconomics for sovereign monetary systems. Springer. 


\section{Loans holdings}

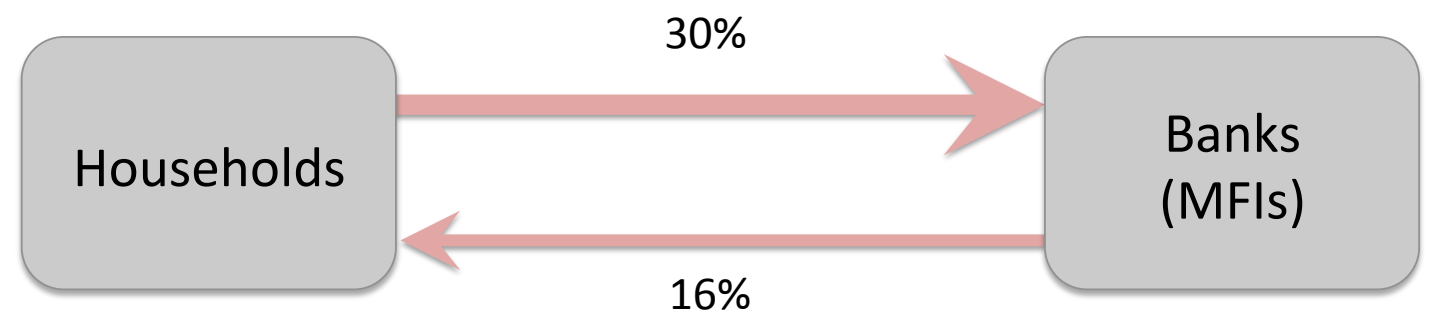

Figure 1: Feedback loop: Banks $\rightarrow$ Households $\rightarrow$ Banks, financial exposures in the Euro Area, stocks (outstanding amounts, fourth quarter of 2015). A pink arrow from households to banks shows deposits of households in banks, an arrow in an opposite direction shows loans of banks to households; both arrows show relative exposure (to total assets of the institutional sector). 


\section{Loans holdings}

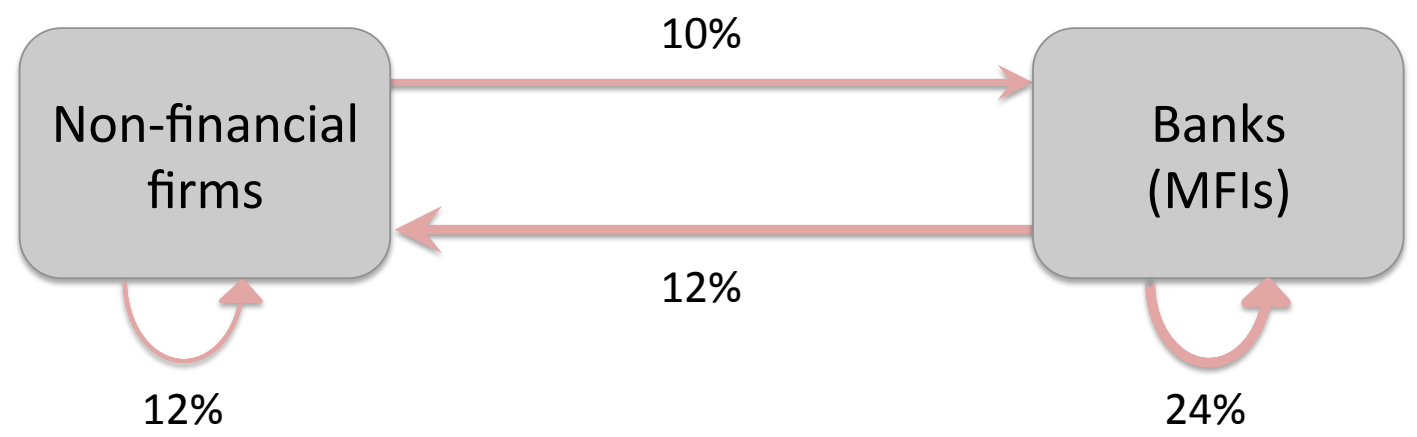

Figure 2: Feedback loop: Banks $\rightarrow$ Firms $\rightarrow$ Firms $\rightarrow$ Banks $\rightarrow$ Banks, financial exposures in the Euro Area, stocks (outstanding amounts, fourth quarter of 2015). A pink arrow from non-financial firms to banks shows deposits of firms in banks, an arrow in an opposite direction shows loans of banks to non-financial firms, selfloops show between the non-financial firms and banks in the Euro Area; all arrows show relative exposure (to total assets of the institutional sector). Note: shock propagates in the opposite direction of the exposure. 
$\longrightarrow$ Life insurance\&pension

schemes

Bonds holdings

Loans holdings

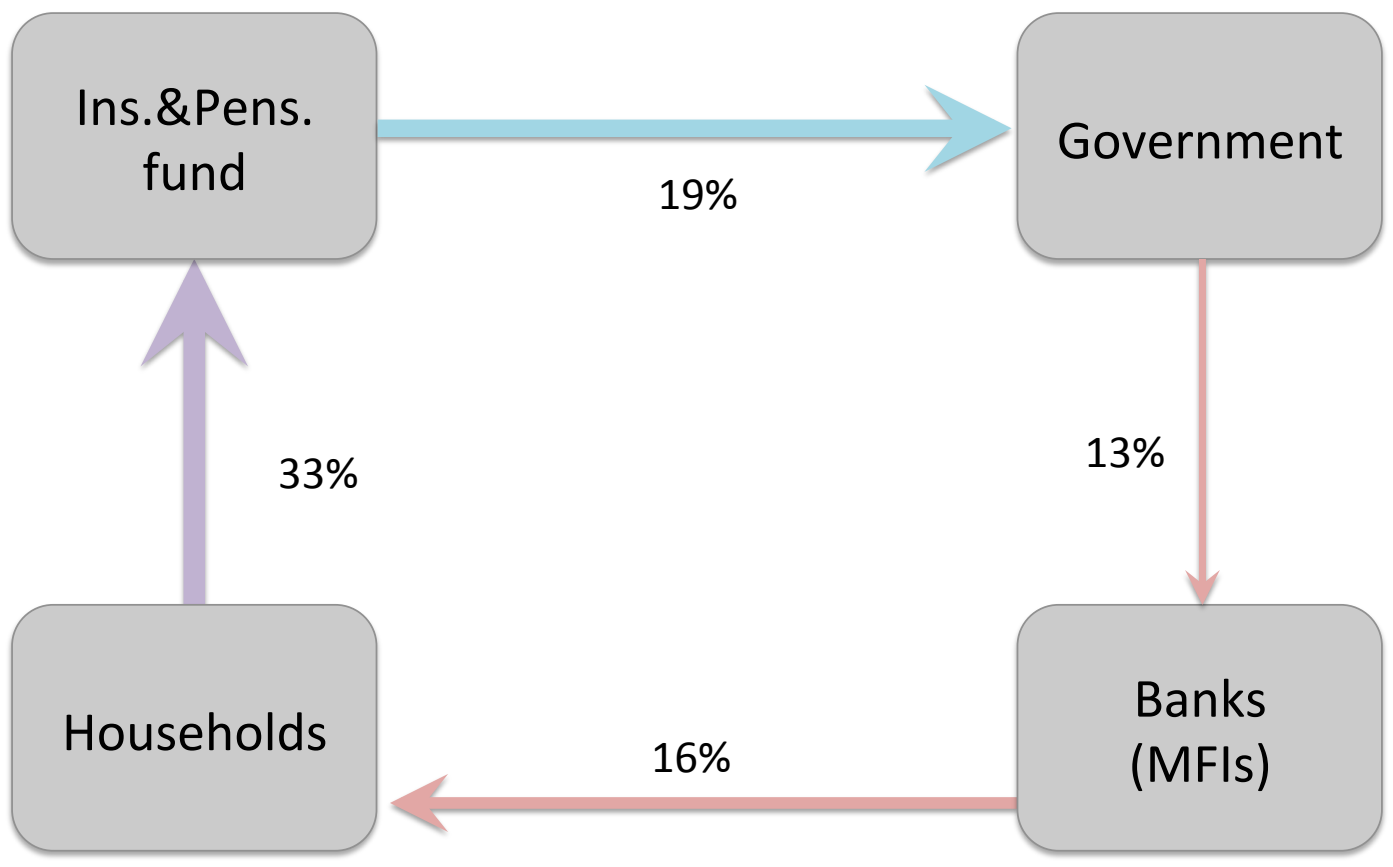

Figure 3: Feedback loop: Banks $\rightarrow$ Government $\rightarrow$ Insurance\&Pension funds $\rightarrow$ Households $\rightarrow$ Banks, financial exposures in the Euro Area, stocks (outstanding amounts, fourth quarter of 2015). Pink arrow from government to banks shows deposits of government in banks, an arrow from banks to households shows loans of banks to households, purple arrow from households to insurance\&pension funds shows life insurance and pension schemes guarantees, blue arrow shows government bond holdings of insurance\&pension funds; all arrows show relative exposure (to total assets of the institutional sector). Note: shock propagates in the opposite direction of the exposure. 
$\longrightarrow$ Life insurance\&pension

schemes

Bonds holdings

Loans holdings

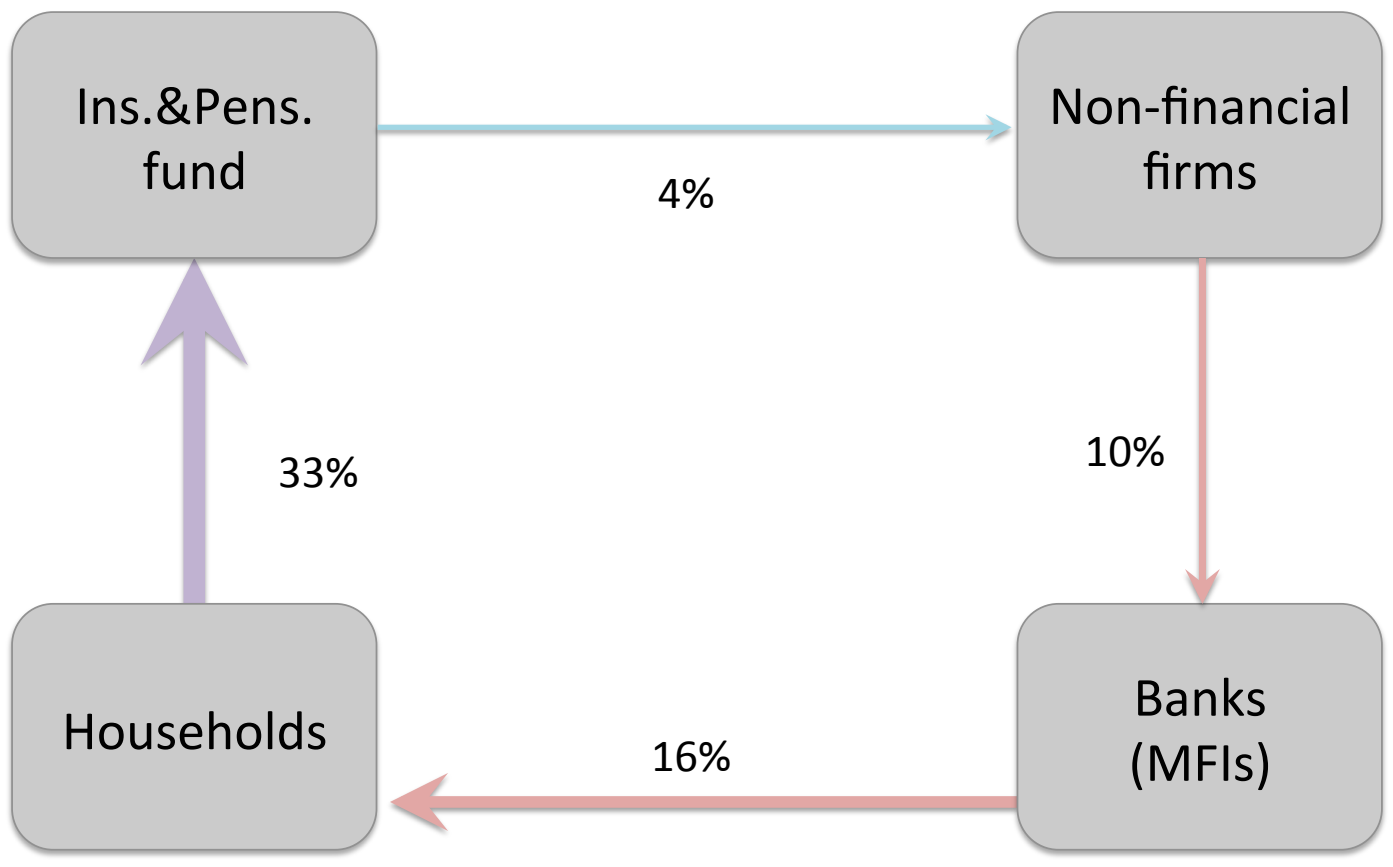

Figure 4: Feedback loop: Non-financial firms $\rightarrow$ Insurance $\&$ Pension funds $\rightarrow$ Households $\rightarrow$ Banks $\rightarrow$ nonfinancial firms, financial exposures in the Euro Area, stocks (outstanding amounts, fourth quarter of 2015). A pink arrow from non-financial firms to banks shows deposits of non-financial firms in banks, an arrow from banks to households shows loans of banks to households, purple arrow from households to insurance\&pension funds shows life insurance and pension schemes guarantees, blue arrow shows corporate bond holdings of insurance\&pension funds; all arrows show relative exposure (to total assets of the institutional sector). Note: shock propagates in the opposite direction of the exposure. 


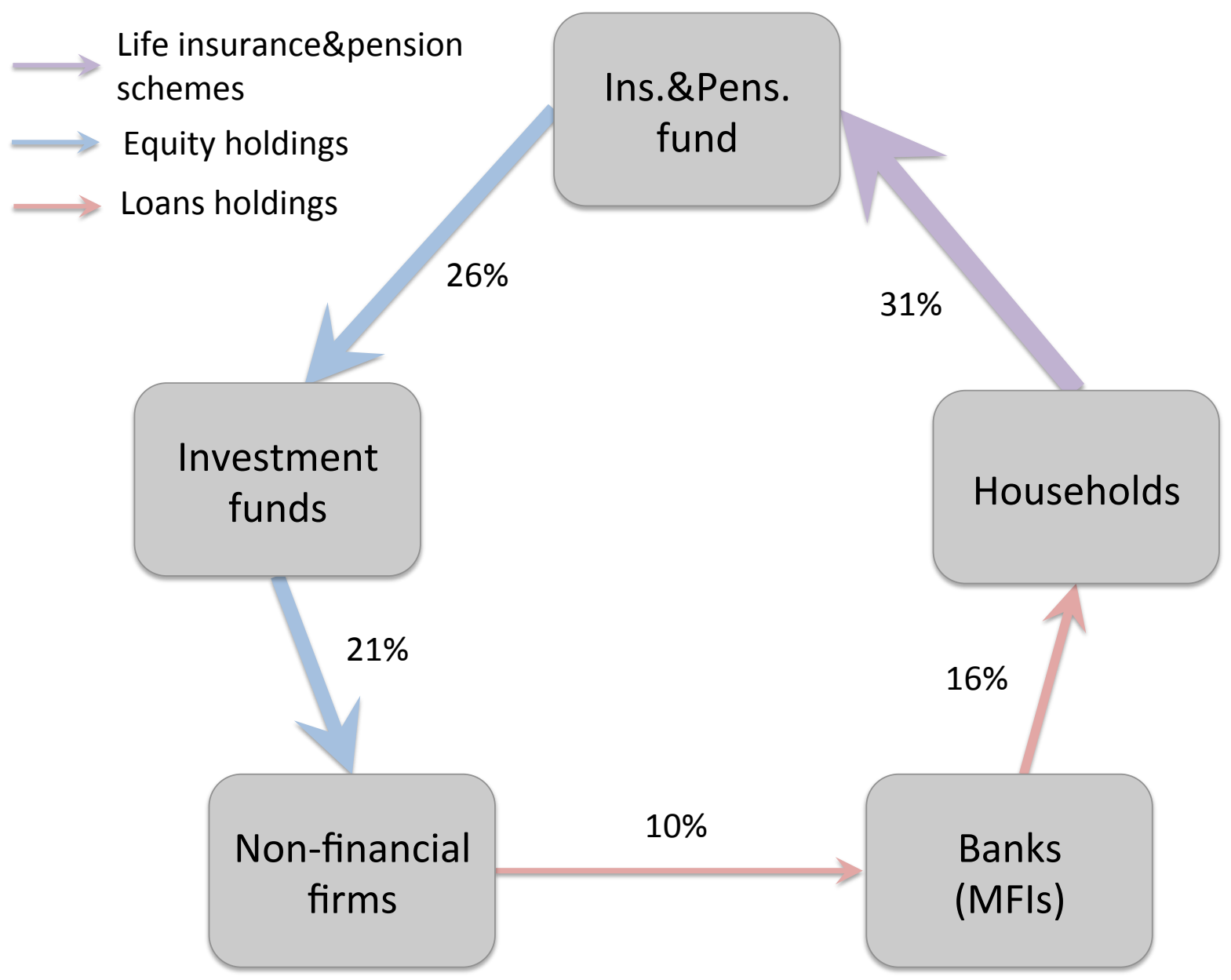

Figure 5: Feedback loop: Non-financial firms $\rightarrow$ Investment funds $\rightarrow$ Insurance\&Pension funds $\rightarrow$ Households $\rightarrow$ Banks $\rightarrow$ non-financial firms, financial exposures in the Euro Area, stocks (outstanding amounts, fourth quarter of 2015). A pink arrow from non-financial firms to banks shows deposits of non-financial firms in banks, an arrow from banks to households shows loans of banks to households, purple arrow from households to insurance\&pension funds shows life insurance and pension schemes guarantees, blue arrow from insurance\&pension funds shows exposure of the Insurance\&pension funds to investment funds through investment fund shares (equity shares) and blue arrow from investment funds shows exposure of the investment funds to non-financial firms; all arrows show relative exposure (to total assets of the institutional sector). Note: shock propagates in the opposite direction of the exposure. 


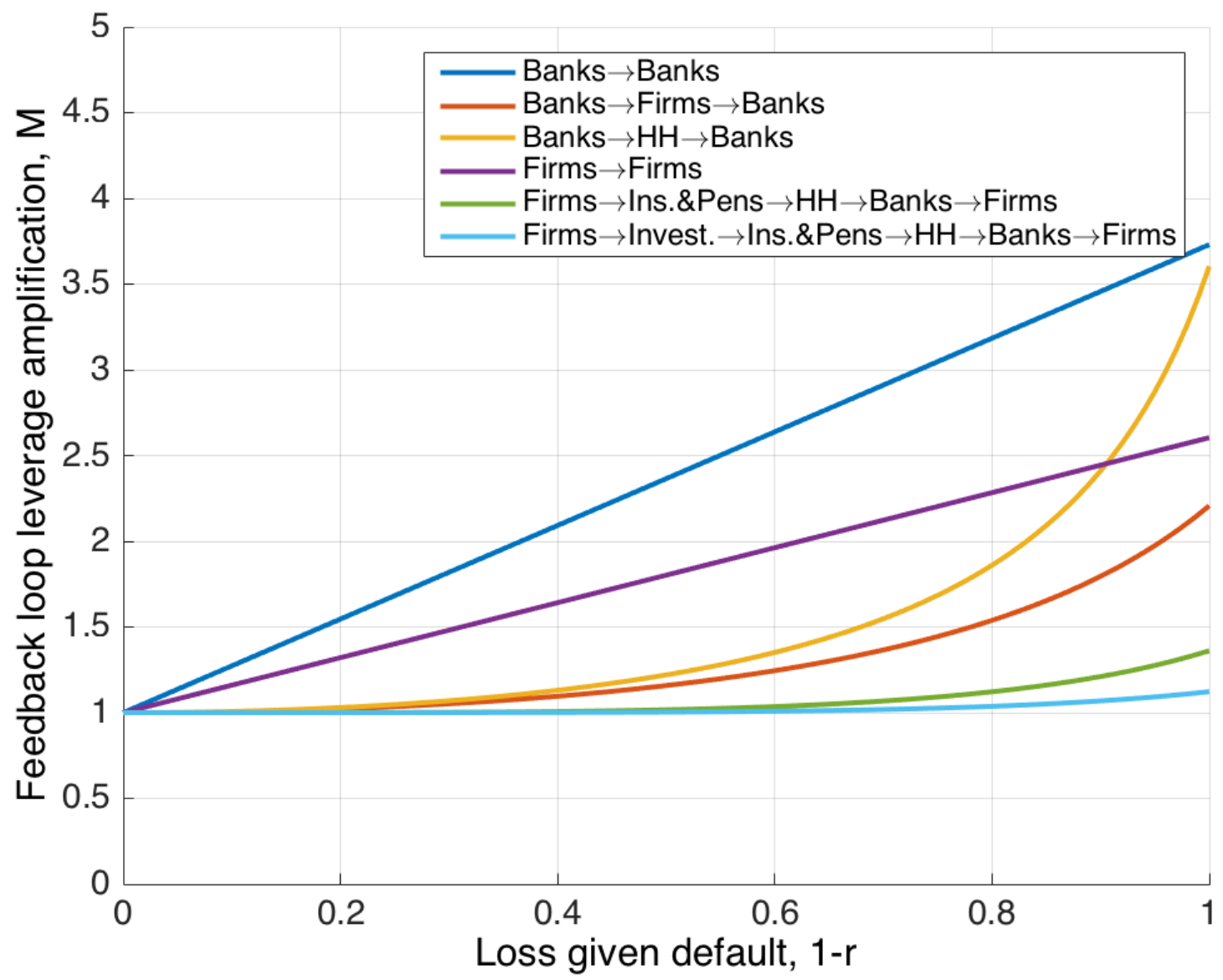

Figure 6: Feedback loop leverage amplification (M) depending on the Loss given default that depends on recovery rate $(r)$ as $(1-r)$. For all feedback loops except for self loops Banks $\rightarrow$ Banks and Firms $\rightarrow$ Firms, the amplified shock converges to a fixed shock, and feedback loop leverage amplification $(M)$ in case of an infinite shock amplification through these feedback loops is finite. For the self-loops of banks and firms, while entering the loop an infinite amount of times, feedback loop leverage amplification $(M)$ increases at each entry and does not converge, therefore, on the figure, $M^{1}$ presented that corresponds to a single entry to the feedback loop as a function of recovery rate of assets for Banks $\rightarrow$ Banks and Firms $\rightarrow$ Firms loops. 


\section{Appendix A. Proofs of Propositions}

Proposition 1 The weighted average of the relative exposure of all firms $l$ in a sector $i$ to all firms $m$ in a sector $j$, weighted by total assets of firms, through instrument $k$, coincides with the aggregate relative exposure of a sector $i$ to a sector $j$ through instrument $k$ :

$$
\frac{\sum_{l}\left(a_{l}^{k} \frac{\sum_{m} a_{l m}^{k}}{a_{l}^{k}}\right)}{\sum_{l} a_{l}^{k}}=\frac{A_{i j}^{k}}{A_{i}^{k}} .
$$

Proof of Proposition 1: The weighted average relative exposure of firms in a sector $i$ to firms in a sector $j$ through instrument $k$ (weighed by total assets of firms $l$ can be written as follows:

$$
\frac{\sum_{l}\left(a_{l}^{k} \frac{\sum_{m} a_{l m}^{k}}{a_{l}^{k}}\right)}{\sum_{l} a_{l}^{k}}=\frac{\sum_{l}\left(\sum_{m} a_{l m}^{k}\right)}{\sum_{l} a_{l}^{k}}=\frac{\sum_{l m} a_{l m}^{k}}{A_{i}^{k}}=\frac{A_{i j}^{k}}{A_{i}^{k}} .
$$

Proposition 2. Assumption: the top q actors by total assets represent $(1-\epsilon)$ of total assets of sector $i$. Then, in the limit of $\epsilon \rightarrow 0$ the aggregate relative exposure of a sector $i$ to a sector $j$ coincides with the average of the exposures of the top $q$ actors, weighted by their total assets, in sector $i$ towards sector $j$.

Proof of Proposition 2: Proposition 2 can be also formulated as follows: if top $q$ firms represent $1-\epsilon$ of total assets of a sector $i$ (where $\epsilon$ is small) then the aggregate relative exposure of a sector $i$ to a sector $j$ (that coincides with the aggregate weighted exposure of actors in a sector $i$ to actors in a sector $j$ according to proposition 1) can be represented as a sum of the weighted average exposure of top $q$ actors of the sector $i$ to the sector $j$ and a function of $\epsilon(f(\epsilon))$ :

$$
\frac{A_{i j}^{k}}{A_{i}^{k}}=\frac{\sum_{l m} a_{l m}^{k}}{A_{i}^{k}}=\frac{\sum_{q m} a_{q m}^{k}}{A_{i}^{k}}+\frac{\sum_{s m} a_{s m}^{k}}{A_{i}^{k}}=\frac{A_{q m}^{k}}{A_{i}^{k}}+\frac{A_{s m}^{k}}{A_{i}^{k}}
$$

where $A_{q m}^{k}=\sum_{q m} a_{q m}^{k}$ is exposure of the top $q$ firms (by assets) of a sector $i$ to firms $m$ in a sector $j$, and $A_{s m}^{k}=\sum_{q m} a_{s m}^{k}$ is exposure of the rest firms (by assets) of a sector $i$ to firms $m$ in a sector $j$. Taking into account that total assets of a sector $i$ through instrument $k$ can 
be decomposed as assets of the top $q$ firms and assets of the rest firms $s$, the total assets of the sector $i$ through instrument $k$ can be written as:

$$
A_{i}^{k}=A_{i}^{k}(1-\epsilon)+A_{i}^{k} \epsilon
$$

Therefore, using Eq. A.4, equation A.3 can be written as follows:

$$
\frac{A_{q m}^{k}}{A_{i}^{k}}+\frac{A_{s m}^{k}}{A_{i}^{k}}=\frac{A_{q m}^{k}}{A_{i}^{k}(1-\epsilon)+A_{i}^{k} \epsilon}+\frac{A_{s m}^{k}}{A_{i}^{k}}=\left(\frac{A_{q m}^{k}}{A_{i}^{k}(1-\epsilon)}-\frac{\epsilon A_{q m}^{k}}{A_{i}^{k}(1-\epsilon)}\right)+\frac{A_{s m}^{k}}{A_{i}^{k}}
$$

Taking into account that $A_{s m}^{k}$ that represents the exposure of the rest of the firms in a sector $l$ that are not included in the top $q$ firms (by assets), the exposure of the rest of the firms to firms $m$ in the sector $j$ can not be larger than total assets of these firms (which is equal to $\epsilon A_{i}^{k}$ ). Therefore, one can represent the exposure of the rest firms in a sector $i$ exposed to the sector $j$ as follows:

$$
A_{s m}^{k}=\alpha \epsilon A_{i}^{k},
$$

where $\alpha$ is a proportionality coefficient between the exposure of the rest firms in a sector $i$ to the firms in the sector $j$ and the total assets of these firms, and $\alpha \leq 1$. Taking into account equations A.6 and A.5, the aggregate relative exposure of a sector $i$ to a sector $j$ can be written as follows:

$$
\left(\frac{A_{q m}^{k}}{A_{i}^{k}(1-\epsilon)}-\frac{\epsilon A_{q m}^{k}}{A_{i}^{k}(1-\epsilon)}\right)+\frac{\alpha \epsilon A_{i}^{k}}{A_{i}^{k}}=\frac{A_{q m}^{k}}{A_{i}^{k}(1-\epsilon)}+\left(\alpha-\frac{A_{q m}^{k}}{A_{i}^{k}(1-\epsilon)}\right) \epsilon=W_{q j}^{k}+\beta \epsilon
$$

where $W_{q j}^{k}$ is the weighted average exposure of the top $q$ firms (by their total assets) of a sector $i$ to a sector $j$ (which following Proposition 1 coincides with aggregate relative exposure of top $q$ firms of a sector $i$ to a sector $j$ ), and $\beta=\left(\alpha-\frac{A_{q m}^{k}}{A_{i}^{k}(1-\epsilon)}\right)$. Taking into account that $\alpha \leq 1$, and $\frac{A_{q m}^{k}}{A_{i}^{k}(1-\epsilon)} \leq 1$, meaning that $\beta \sim 1$, and assuming that $\epsilon$ is small, thus, $\beta \epsilon$ is small too. Therefore, the aggregate relative exposure of a sector $i$ to a sector $j$ with a high level of precision can be represented by the weighted average of exposures of the top $q$ firms (by their total assets) of a sector $i$ to firms in a sector $j$ or by the aggregate relative exposure of the top $q$ firms (by their total assets) of a sector $i$ to firms in a sector $j$. 
Proposition 3. Assumption: for each sector in a closed chain of exposures in a macro-network, all top $q$ actors in a given sector $i$ are linked to at least one of the top $q$ actors in the following sector $j$ in the chain. Then, there exist some closed chains of exposures in the micro-network of financial contracts between the firms in sectors $i$ and $j$.

Proof of Proposition 3. This proposition can be proofed by induction. Basis step: let us consider a case of two sectors. If all top $q$ actors of the sector 1 are linked to at least one (or one) of top $q$ actors in the sector 2. Fulfilling the assumption would also mean that all top $q$ actors of the sector 2 are linked to at least one of the top $q$ actors in the sector 1 . This results in a closed chain of financial contracts on the micro-level between the sectors 1 and 2 , as that actor from the sector 2 that the firms from the sector 1 are connected to is linked back to the sector 1 (considering the assumption). Therefore, the basic step is true. Inductive step: let us suppose that the proposition holds for $n$ sectors, and let us prove that it is also true for $n+1$ sector. Taking into account that the proposition holds for the chain of $n$ sector and considering the assumption that all top $q$ actors in the sector $n$ are connected to at least one of the top $q$ actors in the sector 1 , it means that there exists at least one closed chain in the micro-network of financial contracts between the sectors $1, \ldots, n$. Therefore, the proposition is proved.

Proposition 4. Shock Transmission and Sign of shocks. Financial contracts such as equity holdings and debt securities strictly preserve the sign of the shocks from the obligor to the security holder.

Proof of Proposition 4. The proof follows directly from the definition of the valuation of these two types of securities. Taking into account that if a value of a debt security or equity holding goes down, the assets of the holder decrease, while when the value of a debt security or equity holding goes up, the assets of the holder increase. It is important to note that this proposition can not be extended to the credit default swaps(CDS), in which case a negative shock on the firm can lead to a positive shock for a CDS holder.

Proposition 5. Closed chains of equity holdings or debt securities and reinforcing feedback loops. The following closed chains of contracts can lead to a reinforcing feedback loop both in the case of an initial negative or positive shock: i) a closed chain of only equity 
holdings ii) a closed chain of only debt securities (e.g. both bonds and loans) iii) a closed chain including both equity holdings and debt securities.

Proof of Proposition 5. The proof of i) follows directly by induction from Proposition 1 in the case of equity holdings and from the definition of reinforcing feedback loop. The proof of ii) and iii) follow directly by induction from Proposition 1 in the case of debt securities and from the definition of reinforcing feedback loop.

Remark 3. Items ii) and iii) are consistent with the fact that the expected value of the security cannot exceed the face value (e.g. for bond, loan, deposits and insurance guarantees).

\section{Proposition 6. Closed chains of equity and debt securities and balancing feedback}

loops. A closed chain of contracts of equity or debt securities, either bonds or loans, can not lead to a balancing feedback loop both in the case of an initial negative or positive shock.

Proof of Proposition 6. The proof follows directly by induction from Proposition 1 and from the fact that a balancing feedback loop requires an odd number of changes in sign in the shock transmission along the chain.

\section{Appendix B. ECB definitions of institutional sectors}

1. Non-Financial Corporations (NFC, or non-financial firm $5^{5}$ ) - corporations or quasi-corporations that are not engaged in financial intermediation but are active primarily in the production of market goods and non-financial services.

2. Banks or Monetary Financial Institutions (MFI, or banks) - financial institutions which together form the money-issuing sector of the Euro Area. These include the Euro system, resident credit institutions (as defined in EU law) and all other resident financial institutions whose business is to receive deposits and/or close substitutes for deposits from entities other than MFIs and, for their own account (at least in economic terms), to grant credit and/or invest in securities. The latter group consists predominantly of money market funds (MMFs).

\footnotetext{
${ }^{5}$ https://www.ecb.europa.eu/home/glossary/html/index.en.html
} 
3. Non-MMF Investment Funds (IF). An investment fund is a supply of capital belonging to numerous investors that is used to collectively purchase securities while each investor retains ownership and control of his or her own shares. An investment fund provides a broader selection of investment opportunities, greater management expertise and lower investment fees than investors might be able to obtain on their own. According to European Central Bank Data Warehouse, IFs can be classified into bond funds, equity funds, mixed funds, real estate funds, hedge funds, and other funds.

4. Other Financial Institutions (OFI). An OFI is a corporation or quasi-corporation other than an insurance corporation and pension fund that is engaged mainly in financial intermediation by incurring liabilities in forms other than currency, deposits and/or close substitutes for deposits from institutional entities other than MFIs, in particular those engaged primarily in long-term financing, such as corporations engaged in financial leasing, financial vehicle corporations created to be holders of securitized assets, financial holding corporations, dealers in securities and derivatives (when dealing for their own account), venture capital corporations and development capital companies.

5. Insurance Corporations and Pension Funds (I\&PF). According to the ESA 2010, the insurance corporations subsector consists of all financial corporations and quasi-corporations which are principally engaged in financial intermediation as a consequence of the pooling of risks mainly in the form of direct insurance or reinsurance; the pension funds subsector consists of all financial corporations and quasi-corporations which are principally engaged in financial intermediation as a consequence of the pooling of social risks and needs of the insured persons (social insurance). Pension funds as social insurance schemes provide income in retirement, and often benefits for death and disability.

6. General Governments (Gov) - are defined as comprising resident entities that are engaged primarily in the production of non-market goods and services intended for individual and collective consumption and/or in the redistribution of national income and wealth. Included are central, regional and local government authorities as well as social security funds. Excluded are government-owned entities that conduct commercial operations, such as public enterprises. Central governments include all administrative departments 
of the (central) state and other central agencies whose competence extends over the entire economic territory, except for the administration of social security funds. State governments comprise separate institutional units exercising some of the functions of government (excluding the administration of social security funds) at a level below that of the central government and above that of local government.

7. Households $(H H)$ consists of one or more people who live in the same dwelling and also share meals or living accommodation, and may consist of a single family or some other grouping of people. A single dwelling will be considered to contain multiple households if either meals or living space are not shared. 


\begin{tabular}{|c|c|c|}
\hline $\begin{array}{l}\text { Financial contract } \\
\text { type }\end{array}$ & $\begin{array}{l}\text { Shock transmission } \\
\text { channel type }\end{array}$ & Examples \\
\hline Equity holdings & Securities valuation & $\begin{array}{l}\text { An increase (decrease) in market value of } \\
\text { firm's equity increases (decreases) the value } \\
\text { of the shareholder's asset. }\end{array}$ \\
\hline $\begin{array}{l}\text { Debt securities } \\
\text { holdings }\end{array}$ & Securities valuation & $\begin{array}{l}\text { A decrease in equity (difference between } \\
\text { assets and liabilities) of a debt security issuer } \\
\text { decreases the market value of this debt security } \\
\text { that in turn decreases asset of holder of this } \\
\text { debt security. }\end{array}$ \\
\hline Loans & Securities valuation & $\begin{array}{l}\text { A decrease in creditworthiness of a firm } \\
\text { induces a decrease in the value of the lending } \\
\text { bank's assets. }\end{array}$ \\
\hline $\begin{array}{l}\text { Insurance\&pension } \\
\text { schemes guarantees }\end{array}$ & Securities valuation & $\begin{array}{l}\text { A decrease in income flow from a households' } \\
\text { pension scheme induces a deterioration of the } \\
\text { household's creditworthiness. }\end{array}$ \\
\hline $\begin{array}{l}\text { Deposit, loans,bonds, } \\
\text { equity holdings }\end{array}$ & $\begin{array}{l}\text { Changes in saving/ } \\
\text { investments decisions }\end{array}$ & $\begin{array}{l}\text { A shock on a bank asset induces depositors to } \\
\text { withdraw their funds (bank run). This, in turn, } \\
\text { leads to a decrease in the creditworthiness } \\
\text { of the bank. }\end{array}$ \\
\hline
\end{tabular}

Table 1: Types of shock transmission channels through financial contracts between the actors. 


\begin{tabular}{|c|c|c|c|}
\hline $\begin{array}{l}\text { Policy shock } \\
\text { sector of origin }\end{array}$ & Policy type & Policy example & Direct policy impact \\
\hline Banks & $\begin{array}{l}\text { Unconventional } \\
\text { monetary policies }\end{array}$ & $\begin{array}{l}\text { Green asset } \\
\text { purchasing } \\
\text { programs (green } \\
\text { QE) }\end{array}$ & $\begin{array}{l}\text { Positive shock for banks holding } \\
\text { green assets }\end{array}$ \\
\hline Banks & $\begin{array}{l}\text { Macroprudential } \\
\text { financial } \\
\text { regulation }\end{array}$ & $\begin{array}{l}\text { Differential capital } \\
\text { requirements for } \\
\text { green loans }\end{array}$ & $\begin{array}{l}\text { Positive shock for banks with large } \\
\text { holdings of green loans, negative for } \\
\text { those with large holdings of carbon } \\
\text {-intense loans }\end{array}$ \\
\hline $\begin{array}{l}\text { Non-financial } \\
\text { firms }\end{array}$ & $\begin{array}{l}\text { Market-based } \\
\text { solutions }\end{array}$ & $\begin{array}{l}\text { Carbon tax/ } \\
\text { carbon price }\end{array}$ & $\begin{array}{l}\text { Positive shock for firms in green } \\
\text { sectors, negative shock for those in } \\
\text { carbon-intense sectors }\end{array}$ \\
\hline $\begin{array}{l}\text { Non-financial } \\
\text { firms }\end{array}$ & $\begin{array}{l}\text { Environmental } \\
\text { regulation }\end{array}$ & $\begin{array}{l}\text { Limits on carbon } \\
\text { emissions }\end{array}$ & $\begin{array}{l}\text { Positive shock for firms in low } \\
\text {-carbon sectors, negative for carbon } \\
\text {-intense sectors }\end{array}$ \\
\hline
\end{tabular}

Table 2: Types of policies and policy shocks analyzed. 


\begin{tabular}{|l|l|l|l|l|l|l|l|}
\hline $\begin{array}{l}\text { Balance sheet/ } \\
\text { Sector }\end{array}$ & $\begin{array}{l}\text { Non-fin. } \\
\text { firms }\end{array}$ & Banks & $\begin{array}{l}\text { Invest. } \\
\text { funds }\end{array}$ & $\begin{array}{l}\text { Other Fin. } \\
\text { Inst. }\end{array}$ & $\begin{array}{l}\text { Ins.\& } \\
\text { pens. } \\
\text { funds }\end{array}$ & Gov. & $\begin{array}{l}\text { House- } \\
\text { holds }\end{array}$ \\
\hline $\begin{array}{l}\text { Equity } \\
\text { (unlisted) }\end{array}$ & $\begin{array}{l}7.5 \\
(41 \%)\end{array}$ & $\begin{array}{l}1.4 \\
(3 \%)\end{array}$ & $\begin{array}{l}4.7 \\
(1.7 \%)\end{array}$ & $\begin{array}{l}6.7 \\
(46 \%)\end{array}$ & $\begin{array}{l}3.5 \\
(5.6 \%)\end{array}$ & $\begin{array}{l}1.4 \\
(25.8 \%)\end{array}$ & $\begin{array}{l}4.9 \\
(13 \%)\end{array}$ \\
\hline Bonds & 0.257 & 6.8 & 3.9 & 1.1 & 3.7 & 0.453 & 0.884 \\
\hline Loans/deposits & 6.2 & 22.4 & 0.457 & 7.7 & 1.3 & 1.8 & 6.9 \\
\hline Insurance\&pension & - & - & - & - & 0.324 & - & 7.3 \\
\hline $\begin{array}{l}\text { Equity=Assets- } \\
\text { Liabilities (except } \\
\text { for equity issued) }\end{array}$ & 5.47 & 3.57 & 9.0 & 10.2 & 0.859 & -7.4 & 15.1 \\
\hline Total Liabilities & 31.6 & 31.9 & 9.8 & 18.9 & 9.0 & 12.5 & 7.0 \\
\hline Total assets & 21.2 & 32.4 & 9.5 & 19.5 & 9.2 & 5 & 22 \\
\hline
\end{tabular}

Table 3: Assets of the institutional sectors of the Euro Area by instrument: equity, bonds holdings and loans holdings in trillion $€$. 


\begin{tabular}{|c|c|c|c|c|c|}
\hline $\mathbf{N}$ & Feedback loop & $\begin{array}{l}\text { Examples of shock } \\
\text { type/origin }\end{array}$ & $\begin{array}{l}\text { Exposure } \\
\text { amplifi- } \\
\text { cation, } \\
M\end{array}$ & $\begin{array}{l}\text { Leverage } \\
\text { amplifi- } \\
\text { cation, } M \\
\text { or }\left(M^{1}\right)\end{array}$ & Figure \\
\hline 1 & $\begin{array}{l}\text { Banks } \rightarrow \text { Banks } \\
\text { (self-loop) }\end{array}$ & $\begin{array}{l}\text { Green asset purchasing pro- } \\
\text { grams }\end{array}$ & 1.43 & $(3.73)$ & \\
\hline 2 & $\begin{array}{l}\text { Banks } \rightarrow \text { Firms } \\
\rightarrow \text { Banks }\end{array}$ & $\begin{array}{l}\text { Differential capital require- } \\
\text { ments for green loans }\end{array}$ & 1.02 & 2.21 & \\
\hline 3 & $\begin{array}{l}\text { Banks } \rightarrow \text { Firms } \\
\rightarrow \text { Firms } \rightarrow \text { Banks } \\
\rightarrow \text { Banks }\end{array}$ & $\begin{array}{l}\text { Differential capital require- } \\
\text { ments for green loans }\end{array}$ & 1.00 & $(3.40)$ & Figure 2 \\
\hline 4 & $\begin{array}{l}\text { Banks } \rightarrow \text { HH } \\
\rightarrow \text { Banks }\end{array}$ & $\begin{array}{l}\text { Green asset purchasing pro- } \\
\text { grams }\end{array}$ & 1.06 & 3.60 & Figure 1 \\
\hline 5 & $\begin{array}{l}\text { Banks } \rightarrow \text { Gov. } \\
\rightarrow \text { Banks }\end{array}$ & $\begin{array}{l}\text { Differential capital require- } \\
\text { ments for green loans }\end{array}$ & 1.02 & 1.13 & \\
\hline 6 & $\begin{array}{l}\text { Banks } \rightarrow \text { Gov. } \\
\rightarrow \text { Ins.\&Pens. } \\
\rightarrow \mathrm{HH} \rightarrow \text { Banks }\end{array}$ & $\begin{array}{l}\text { Differential capital require- } \\
\text { ments for green loans }\end{array}$ & 1.00 & 1.16 & Figure 3 \\
\hline
\end{tabular}

Table 4: Examples of feedback loops originating in banks, examples of climate policy shocks, the magnitude of amplification factor for exposure amplification and leverage amplification (with its upper bound for $\mathrm{r}=0$ ). Rows sorting: by increasing length of the feedback loop. Amplification values are computed for exposures through all major financial instruments together (equity, bonds, loans, insurance\&pension schemes guarantees) and for the case of infinite number of entries in the feedback loop, except for values in brackets, that corresponds to a single entry to the feedback loop. Note: For most of the feedback loops analyzed, multiple entries to the loop results in an increased but finite shock amplification. For the loops that infinitely amplify the shock, we compute only the amplification through the first entry of the loop ( $M^{1}$ value in brackets). The shocks' amplification corresponds to the recovery rate equal to zero $(r=0)$. This Table lists only several examples of climate policies that are discussed in the literature the most. Listed feedback loops are the largest by financial exposure with length up to five sectors (Section 3.3). 


\begin{tabular}{|c|c|c|c|c|c|}
\hline $\mathbf{N}$ & Feedback loop & $\begin{array}{l}\text { Examples of shock } \\
\text { type/origin }\end{array}$ & $\begin{array}{l}\text { Exposure } \\
\text { amplifi- } \\
\text { cation, } \\
M\end{array}$ & $\begin{array}{l}\text { Leverage } \\
\text { amplifi- } \\
\text { cation, } M \\
\text { or }\left(M^{1}\right)\end{array}$ & Figure \\
\hline 1 & $\begin{array}{l}\text { Firms } \rightarrow \text { Firms } \\
\text { (self-loop) }\end{array}$ & Carbon tax/carbon price & 1.71 & $(2.60)$ & \\
\hline 2 & $\begin{array}{l}\text { Firms } \rightarrow \text { Banks } \rightarrow \\
\text { Firms }\end{array}$ & Limits on carbon emissions & 1.02 & 2.21 & \\
\hline 3 & $\begin{array}{l}\text { Firms } \rightarrow \\
\text { Insur.\&Pens. } \rightarrow \\
\text { HH } \rightarrow \text { Banks } \rightarrow \\
\text { Firms }\end{array}$ & $\begin{array}{l}\text { Environmental regulation of } \\
\text { firms }\end{array}$ & 1.00 & 1.36 & Figure 4 \\
\hline 4 & $\begin{array}{l}\text { Firms } \rightarrow \text { Inv. } \\
\text { funds } \rightarrow \\
\text { Insur.\&Pens. } \rightarrow \\
\text { HH } \rightarrow \text { Banks } \rightarrow \\
\text { Firms }\end{array}$ & $\begin{array}{l}\text { Environmental regulation of } \\
\text { firms }\end{array}$ & 1.00 & 1.12 & Figure 5 \\
\hline
\end{tabular}

Table 5: Examples of feedback loops originating in the firms sector, examples of climate policy shocks, the magnitude of amplification factor for exposure amplification and leverage amplification (with its upper bound for $\mathrm{r}=0$ ). Rows sorting: by increasing length of the feedback loop. Amplification values are computed for exposures through all major financial instruments together (equity, bonds, loans, insurance\&pension schemes guarantees) and for the case of infinite number of entries in the feedback loop, except for values in brackets, that correspond to a single entry to the feedback loop. Note: For most of the feedback loops analyzed, multiple entries to the loop result in an increased but finite shock amplification. For the loops that infinitely amplify the shock, we compute only the amplification through the first entry of the loop. The shocks' amplification presented in columns 5 and 6 corresponds to the recovery rate equal to zero $(r=0)$. This Table lists only several examples of climate policies that are discussed in the literature the most. The feedback loops listed in this Table are the largest feedback loops in terms of financial exposure between the sectors, with feedback loop length up to five sectors (please see Section 3.3 for details). 